NBSIR 74-394

\title{
A RACK-MOUNTED PRECISION WAVEGUIDE-BELOW-CUTOFF attenUator WITH AN ABSOLUTE ELECTRONIC READOUT
}

Clarence C. Cook

Electromagnetics Division

Institute for Basic Standards

National Bureau of Standards

Boulder, Colorado 80302

November 1974

Prepared for

Jet Propulsion Laboratory

Pasadena, California 91103 

NBSIR 74-394

\section{A RACK-MOUNTED PRECISION WAVEGUIDE-BELOW-CUTOFF ATTENUATOR WITH AN ABSOLUTE ELECTRONIC READOUT}

Clarence C. Cook

Electromagnetics Division

Institute for Basic Standards

National Bureau of Standards

Boulder, Colorado 80302

Certain commerical equipment and materials are identified on the drawings in order to adequately specify the fabrication procedure. In no case does such identification imply recommendation or endorsement by the National Bureau of Standards, nor does it imply that the material or equipment identified is necessarily the best available for the purpose.

November 1974

Prepared for

Jet Propulsion Laboratory

Pasadena, California 91103

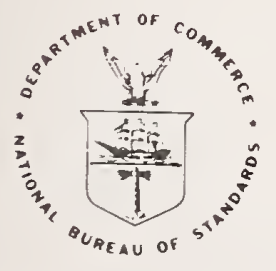

U.S DEPARTMENT OF COMMERCE. Frederick B. Dent. Secretary 

ABSTRACT •. . . . . . . . . . . . 1

1. INTRODUCTION . . . . . . . . . . . . . . 1

2. THEORY OF OPERATION . . . . . . . . . . . . 1

3. DESCRIPTION OF ATTENUATOR .......... 3

4. ATTENUATOR OPERATION . . . . . . . . . . . 7

4.1 Preliminary Setup and Check . . . . . . 7

4.2 Displacement Readouts and Attenuation Value 7

5. OPERATIONAL CONSIDERATIONS • • . • . . • . . 9

5.1 Initial Alignment . . . . . . . . . . 9

5.2 Operation . . . . . . . . . . . . 10

6. ERROR ANALYSIS . . . . . . . . . . . . . 11

6.1 Waveguide Diameter . . . . . . . . . Il

6.2 Waveguide Conductivity . . . . . . . 12

6.3 Attenuation Rate . . . . . . . . . 12

6.4 Displacement Readout . . . . . . . . 13

6.5 Miscellaneous Sources of Error..... . 13

6.6 Temperature Effects . . . . . . . . 15

6.7 Summary of Errors . . . . . . . . . 16

7. SUMMARY . . . . . . . . . . . . . 16

8. ACKNOWLEDGMENTS . • . . . . . . . . . . . 17

9. REFERENCES . . . . . . . . . . . . . . 17

10. PARTS LIST . . . . . . . . . . . . . 18 


\section{LIST OF FIGURES}

Page

1. Front view of attenuator . . . . . . . . . 20

2. Top view of attenuator . . . . . . . . . . 21

3. Top view of attenuator with various parts labeled 22 4(a)-4(s) Machine drawings of attenuator . . . 23-41

\section{LIST OF TABLES}

I. Attenuation rate of piston attenuator at ambient temperature of 68 degrees F . . . . . . . . . 13

II. Attenuation rate of piston attenuator at ambient temperature of 72 degrees F . . . . . . . 15 


\section{ABSTRACT}

A coaxial precision waveguide-below-cutoff attenuator is described which utilizes an absolute (unambiguous) electronic digital readout of displacement in inches in addition to the usual geardriven mechanical counter/dial readout in decibels. The attenuator is rack-mountable and has the input and output rf connectors in a fixed position. The attenuation rate for 55, 50, and $30 \mathrm{MHz}$ operation is given along with a discussion of sources of errors. In addition, information is included to aid the user in making adjustments on the attenuator should it be damaged or disassembled for any reason.

KEY WORDS: Absolute (unambiguous) readout; piston; precision attenuator; sensor; waveguidebelow-cutoff.

\section{INTRODUCTION}

This paper briefly describes the construction and operation of a waveguide-below-cutoff attenuator designed to operate at a primary frequency of $50 \mathrm{MHz}$ with possible future operation at 55 or $30 \mathrm{MHz}$. This attenuator (fig. 1) has some unique features: 1) it is rack-mountable; 2) it has fixed input and output rf connectors at the back of the attenuator assembly; and 3) it has an absolute (unambiguous) electronic digital readout of the linear displacement in inches, in addition to a more common mechanical readout in decibels.

\section{THEORY OF OPERATION}

The waveguide-below-cutoff attenuator, [1,2] * commonly called a piston attenuator, is a section of waveguide operated at a frequency far below the cutoff frequency of the waveguide. Thus, the field strength in the guide decreases

* Numbers in brackets refer to the references given at the end of this paper.

References $[1,2]$ contain extensive bibliographies on all phases of attenuation measurements as well as waveguidebelow-cutoff and other common types of attenuators. Therefore the number of references used in this paper is kept to a minimum. 
exponentially along the longitudinal axis of the guide. Many modes can exist in a waveguide. The rate of decay of these modes below cutoff increases as the cutoff Erequency increases. The riode having the lowest decay rate and lowest cutoff frequency is called the dominant mode and is the mode used in most piston attenuators. For practical considerations, the circular waveguide is the most common shape used. The attenuator described here operates in the dominant mode in circular waveguide, namely, the $\mathrm{TE}_{11}$ mode. The attenuation rate of the ideal piston attenuator is given by $\frac{p_{n m}}{a}$, where a is the radius of the guide and $p_{n m}$ is a constant determined by the waveguide configuration and the mode of operation. For the circular $\mathrm{TE}_{11}$ mode, $\mathrm{p}_{11}$ equals I. 84118378 and is the first root of the first derivative of the first-order Bessel function of the first kind. For a practical circular-waveguide piston attenuator, the attenuation rate is affectea sightly by the finite conductivity of the guide wall and the ratio of cutoff frequency to operating frequency. The actual rate is closely approximated by the following equation:

$$
A=\frac{p_{1} 1}{a} \sqrt{1-\frac{\delta}{a}-\left(\frac{f}{f_{c}}\right)^{2}},
$$

Where

$A$ is the attenuation rate

$\delta$ is the skin depth of the guide $=\frac{1}{\sqrt{\pi \mu f \sigma}}$

$f_{C}$ is the cutoff frequency $=\frac{P_{11 C}}{2 \pi a}$

$\mu$ is the permeability of the guide

$\sigma$ is the conductivity of the guide

$c$ is the velocity of propagation in free space and MiRs units are assumed thxoughout. This equation can be approximateả as follows: 


$$
A=\frac{15.99232}{a}\left[1-\frac{\delta}{2 a}-\frac{1}{2}\left(\frac{f}{f_{C}}\right)^{2}\right],
$$

where

$A$ is in $d B /$ inch, and

a is now in inches

of all the factors involved in the second-order corrections, only the conductivity $(\sigma)$ is not known to sufficient accuracy to leave no uncertainty in these corrections.

Extra modes must not exist in a piston attenuator if high accuracy is desired. For the $\mathrm{TE}_{11}$ mode attenuator, the most bothersome mode is the $\mathrm{TM}_{01}$ mode, which has the second lowest rate of attenuation. Fortunately, a simple mode filter consisting of several grounded metal strips perpendicular to the $\mathrm{TE}_{11}$ electric field will attenuate the $\mathrm{TM}_{0}$ mode by at least $60 \mathrm{~dB}$ while decreasing the desired mode by less than $0.5 \mathrm{~dB}$.

\section{DESCRIPTION OF ATTENUATOR}

The basic piston attenuator consists of four principal parts: the circular waveguide or main body of the attenuator, the exciting unit, the receiving unit, and the mode filter. The waveguide is a brass cylinder whose inside diameter is accurately machined to a known uniform value. During the fabrication process, this guide was stress-relieved several times to minimize any tendency for dimensional creep and to keep the rf conductivity of the wall as near as possible to that of the bulk material. A rhodium flash of a few microinches thickness was applied to the inner surface to minimize surface tarnishing. 
The exciting unit [3] consists of a five-turn coil, wh Impedance matching network, and an rf input connector--a 11 mounted in a metal housing which is screwed onto the input. and of the guide. The coil, when current is applied to it, establishes the TEl mode field in the guide, the electric field lines being parallel to the wires of the coil. The matching network transforms the low inductive reactance of the coil to a resistive 50 ohms. It consists of four miniature glass piston capacitors. These are used in two parallel combinations to double the effective capacitive range of each. One combination is mounted in shunt with the coil and the other combination is mounted in series with the rf input. The shunt capacitors are adjusted to give an impedance of 50 + jx due to partial resonance of the coil-capacitance circuit. The series capacitors are adjusted to a value of -jx. This gives an input impedance of $50+j 0$ ohms. Interaction between the capacitors causes the adjustment of the matching network in an actual attenuator to be much more complicated than in the ideal case, however. The coil and matching network result in a moderately high-Q circuit which is operated very close to parallel resonance. Thus the input impedance is quite sensitive to changes in coil inductance, matching network capacitances, coil losses, and operating frequency. To significantly decrease these effects, the coil in this attenuator has been shunted by a $2 \mathrm{~K}$-ohm rf resistor to effectively lower the $Q$ to a reasonable value. In additicis, this increases the bandwidth of the attenuator, which is of particular interest to the users of this attenuator.

The receiving unit consists of the following: a shunted coil and matching network similar to the ones in the exciting unit; metal contact fingers to provide ground contact to the guide wall and prevent signal leakage past 
this unit, a notched teflon guide to keep the receiving unit centered in the guide as the unit moves longitudinally, and an rf output connector. The receiving coil is parallel to the exciting coil and extracts a small portion of the field as it moves along the guide. This extracted field is proportional to the field strength; thus, the ratio of the extracted fields for two receiving unit locations in the guide is determined by the linear displacement between these points and the attenuation rate of the guide.

The mode filter consists of a metal ring and 15 metal strips, 0.025 inch wide, equally spaced perpendicular to the diameter of the ring. The filter is mounted in the quide between the exciting and receiving coils with the strips perpendicular to the coil elements. It is located approximately 0.036 inches from the end of the exciting coil.

The basic attenuator has been described. To use this device, a manner of moving the receiving unit and a precise indication of the amount of this movement must be provided. The receiving unit is mounted to one end of a precision lead screw. A captive nut moves the screw along the quide.* The screw is keyed to prevent rotation of the receiving unit. Rapid movement of the receiving unit (piston) is provided by driving the nut with an electric motor. Also connected to the nut throuqh suitable gears are a mechanical counter and an engraved circular dial. These give a mechanical readout of the receiving unit location. In addition, a knob on the dial provides the control for fine positioning of the attenuator manually after the approximate position is reached with the motor drive. An optical sensor and associated electronics provide an accurate digital display of the piston

* The correspondina motion of the receiving unit inside the guide can be compared to the motion of a piston in a cylinder. Thus, this unit is frequently referred to as the "piston." In fact, this is the origin of the name "piston attenuator." 
position independently of the mechanical readout. An auxiliary BCD output is available from the sensor, also. Semi-rigid 3-mm coaxial cable is run through a hole along the axis of the lead screw to bring the rf signal out of the attenuator. This is connected to one end of a solenoidal coil of similar cable. The other end of the coiled cable connects to the type $\mathrm{N}$ output connector on the back panel. The coil of cable is used to minimize effects of cable motion which is unavoidable when the receiving unit moves.

A cross arm is fastened securely to the back end of the lead screw. To keep this arm from twisting during operation of the attenuator, the outer ends are guided by low-friction linear roller bearings mounted on precision circular guide rods. The push rod of the displacement sensor is fastened to one side of the cross arm and the movable end of the coiled cable is fastened to the other side. These details can be seen by referring to figures 2 and 3 .

The complete attenuator consists of two rack-mounted packages. The attenuator assembly contains the basic attenuator, drive motor, mechanical readout and associated gearing, all rf cables and connections, and the electronic sensor. The readout assembly contains the digital display of the attenuator displacement, BCD output connector, datum shift switches, and all necessary electronics required by the displacement sensor and readout. 


\section{ATTENUATOR OPERATION}

\section{I Preliminary Setup and Check}

To place the attenuator into operation, connect the two cables to the readout assembly and attenuator assembly by mating the marked multi-pin plugs to the corresponding sockets. Make the necessary connections to the rf input and output. Connect each assembly to an ac power source and turn on the readout unit. A six-digit display should be obtained with the least significant (far-right) digit always even. The display is now indicating the position of the piston of the attenuator. This display is in inches and has a resolution of 20 microinches. Rotating the attenuator manual control knob should cause a change in the display.

\subsection{Displacement Readouts and Attenuation Value}

As mentioned previously, two independent readouts of the attenuator piston displacement are provided.

The mechanical readout consists of a 5-digit mechanical counter and a circular dial. The counter reads in $\mathrm{dB}$ in 0.1 $\mathrm{dB}$ increments (a decimal point is assumed to precede the far-right digit) while the dial indicates 0 to $0.1 \mathrm{~dB}$ in 0.001 $\mathrm{dB}$ increments for each one-half revolution of the dial. The attenuation value in $\mathrm{dB}$ is obtained by adding the counter reading and the last two digits of the dial reading with the exception noted below. Since the right "tenths" digit of the counter does not change at exactly .000 or .100 dial settings, and one revolution of the dial corresponds to two counts on the counter, a certain rule must be followed here. If the left digit of the dial is "O" and the right digit of the counter is odd, subtract one count from this counter reading. Likewise, if the left digit of the dial is "l" and the right digit of the counter is even, subtract one count 
from this counter reading. For example, if the counter reading is 31.2 and the dial reading is .065 , the attenuation value is $31.265 \mathrm{~dB}$, whereas readings of 31.3 and .095, respectively, correspond to a value of 31.295 and not 31.395 (in this case, the counter has changed from 31.2 to 31.3 prior to the dial reaching .100). Likewise, counter and dial readings of 11.1 and .132 correspond to an attenuation value of 11.132, whereas readings of 11.2 and .198 correspond to a value of 11.198 .

The electronic readout provides a direct digital readout of the piston displacement in inches with the least increment being 20 microinches. Multiplication of this reading by 20 converts to decibels since the nominal attenuation rate of this attenuator is $20 \mathrm{~dB} / \mathrm{inch}$. Thus, the resolution of this display is $0.0004 \mathrm{~dB}$. Datum switches on the readout unit permits the display to be zeroed or set to any desired value at any attenuator setting.

As with any attenuator, a known change in attenuation can be made only by taking the difference between two settings of the attenuator. Thus, the final setting of the attenuator minus the initial setting gives the net change in the attenuation. Of course, this may be positive or negative. If the electronic readout is used, the difference in the two readings is in inches and must be converted to decibels. Here, if the datum switches are used to zero the display in the initial position, the final display will give the net change directly in inches. 


\section{OPERATIONAL CONSIDERATIONS}

\subsection{Initial Alignment}

These alignments are made during assembly of the attenuator and ordinarily are not attempted by the user. However, should circumstances warrant repair or adjustment by the user, the following information may be useful.

The exciting and receiving units are mounted such that the wire elements of the two units are in the same vertical plane as seen looking down the guide. Since the relative coupling is proportional to the cosine of the angle between these coils, visual alignment is adequate for this purpose. Rotation of the receiving unit during attenuator operation must not be allowed, however. Similarly, visual alignment of the mode filter to put the filter elements perpendicular to the exciting elements is satisfactory.

Four small holes in the excitation unit housing permit adjustment of the capacitors to match the input impedance of the attenuator to $50 \mathrm{ohms}$. The use of a vector impedance meter to monitor the input impedance simplifies the procedure. The series and shunt capacitors alternate around the adjustment hole circle. As the adjustment screws of the series capacitors are part of the input circuit, these must be tuned by making an adjustment and removing the screwdriver from contact before reading the impedance. The excitation unit should be in place on the guide before tuning as the mode filter and attenuator barrel affect the impedance. To avoid heating effects, the rf power to this unit should not exceed 250 milliwatts. Adjustment of the receiving unit is done in a similar manner. Unfortunately, the tuning capacitors cannot be reached without disassembling this end of the attenuator. 
A certain minimum value of insertion loss must be maintained in a piston attenuator in order to prevent interaction between exciting and receiving units, keep undesired modes at an insignificant level, and prevent excessive coupling of the $\mathrm{TE}_{11}$ field to the receiving unit. Otherwise, high precision cannot be attained. This minimum insertion loss has been determined to be approximately $30 \mathrm{~dB}$. Therefore, the mechanical readout has been set to zero at a nominal insertion loss of $30 \mathrm{~dB}$ at $50 \mathrm{MHz}$. The datum switches were set so that the electronic readout was approximately zero at this setting, also; however, these switches may be readjusted as desired.

\subsection{Operation}

The attenuator is operated by moving the motor switch to the left to decrease attenuation or to the right to increase it. Limit switches turn the motor off if it runs below 0 or above about $53 \mathrm{~dB}$, respectively. When the approximate value of attenuation is reached, the motor is turned off and the final adjustment made by using the manual control.

CAUTION: Never reverse the motor direction without coming to a complete stop first. When using the mechanical readout, always approach a given attenuator setting in the same direction to minimize effects of backlash in the nut and gears.

Operation and maintenance of the electronic displacement readout and sensor are explained by a comprehensive manual provided by the manufacturer and will not be covered any further here. 


\section{ERROR ANALYSIS}

For convenience, the equation for the attenuation rate is rewritten here in slightly different form.

$$
A=\frac{15.99232}{a}\left[1-\frac{1}{2 a \sqrt{\pi \mu f \sigma}}-\frac{1}{2}\left(\frac{2 \pi a f}{p_{11}^{c}}\right)^{2}\right]
$$

It is readily seen that the guide radius is by far the most critical factor in determining the attenuation rate and that the uncertainty in this dimension will cause the largest uncertainty in the attenuation rate. The total correction due to finite conductivity is about $0.0093 \mathrm{~dB} /$ inch and that for finite cutoff frequency is about $0.0016 \mathrm{~dB} / \mathrm{inch}$. The only significant uncertainty in these corrections is that resulting from the uncertainty in the conductivity determination.

\subsection{Waveguide Diameter}

The inside diameter of the attenuator guide was measured by an air gauge at an ambient temperature of $68^{\circ} \mathrm{F}$. Measurements were sampled every half inch along the center three inches of the guide. Three readings were taken at each point, equally spaced around the circumference. The average diameter was found to be 1.598347 inches with longitudinal variations in the average diameter of \pm 13 microinches. The maximum variation around the circumference at any point was \pm 9 microinches. The measurements are believed accurate to \pm 20 microinches. Therefore, the diameter of the guide can be given as $1.598347 \pm 33 \times 10^{6}$ inches. The uncertainty in diameter causes an uncertainty in the attenuation rate of $\pm 0.0004 \mathrm{~dB} /$ inch. 
Although equation (3) shows that the radius, a, is involved in both correction terms, these are second-order terms and are affected very little by small variations in the radius. This fact is very useful in calculating the attenuation rate of a piston attenuator. Assume that one has used equation(3) to determine the attenuation rate, $A_{1}$, corresponding to an approximate radius, $a_{1}$. Then the radius, $\mathrm{a}_{2}$, required to give the desired rate of $\mathrm{A}_{2}$ is quickly determined by the following relations:

$$
A_{2}=A_{1} \frac{a_{1}}{a_{2}} \text { or } a_{2}=a_{1} \frac{A_{1}}{A_{2}}
$$

\subsection{Waveguide Conductivity}

The bulk conductivity of the brass waveguide was measured at dc. Based on the findings of several researchers in the field, the effective rf conductivity at $55 \mathrm{MHz}$ is estimated to be 5\% lower than the dc value. This gives a value of $1.30 \times 10^{7} \mathrm{mho} /$ meter. The uncertainty in this value may be as much as $10 \%$. This gives an uncertainty in the attenuation rate of $\pm 0.0005 \mathrm{~dB} /$ inch.

\subsection{Attenuation Rate}

From the above, the total uncertainty in the attenuation rate is less than $\pm 0.001 \mathrm{~dB} /$ inch at $55 \mathrm{MHz}$. This is essentially the same at 50 and $30 \mathrm{MHz}$ as well. The attenuation rate based on a diameter of 1.598347 inches and rf conductivity of $1.30 \times 10^{7} \mathrm{mho} /$ meter is given in table $\mathrm{I}$. 
Table I

Attenuation Rate of Piston Attenuator at Ambient Temperature of 68 degrees $\mathrm{F}$

Frequency of Operation

$\mathrm{MHz}$

55

50

30
Attenuation Rate

$\mathrm{dB} /$ Inch

20.00018

20.00000

19.99803

\subsection{Displacement Readout}

The uncertainty in measuring the displacement of the piston from its initial to its final value is almost always the source of the greatest uncertainty in piston attenuators. Only by the use of ultraprecise length measuring systems such as laser-interferometers or the system used on this attenuator can this source of error be reduced to a reasonable value. The variation in the lead of the lead screw over a oneinch span was 0.00012 inches. This causes an uncertainty in attenuation of $0.0024 \mathrm{~dB} /$ inch.

The uncertainty in the electronic readout is probably less than 50 microinches over its entire range. This gives an uncertainty of $0.001 \mathrm{~dB}$ over the range of $50 \mathrm{~dB}$.

\subsection{Miscellaneous Sources of Error}

By use of a mode filter and approximately $30 \mathrm{~dB}$ minimum insertion loss, the effect of other modes is believed to be negligible at the attenuator zero setting. With increasing attenuation, the effect of spurious modes is reduced still further. The ratio of $\mathrm{TM}_{01}$ to $\mathrm{TE}_{11}$ mode strength is reduced by a factor of 2 for each $20 \mathrm{~dB}$ increase in attenuation. 
Optimum layout of the displacement sensor for the electronic readout is in line with the lead screw. However, space limitations necessitated mounting the sensor parallel to the attenuator guide with the axis of the push rod being offset about five and one-fourth inches from the axis of the lead screw. Any twisting or cocking of the cross arm between the two positions of the piston during an attenuation measurement would produce an erroneous reading. It is believed that this effect is negligible if the roller bearings and guides and the sensor bearings are clean and running freely as when the attenuator left NBS. However, should any of the bearings become contaminated by dust or dirt causing erratic movement, errors would occur. Such a condition probably could be detected by an inability to repeat an attenuation value, tendency of the electronic readout to creep after the piston motion has ceased, or tendency to get changes in readings when the attenuator is jarred slightly. A small change in the readout upon being jarred may be normal, e.g., the relaxing of the forces built up between the nut and lead screw due to motion of the piston in one direction.

Leakage from the attenuator is believed to be negligible for all values of attenuation from 0 to $50 \mathrm{~dB}$.

The input and output impedances are adjusted to 50 ohms resistive to avoid reflections when the attenuator is inserted in a 50-ohm system. The match is not essential to proper operation of the device and moderate mismatches would only increase the initial insertion loss due to mismatch losses. However, high standing waves in the interconnecting rf cables would increase the possibility of leakage from these cables. 


\subsection{Temperature Effects}

Temperature changes have a very definite effect upon the attenuation rate; namely, the percentage change in attenuation rate is the negative of the percentage change in guide radius. The coefficient of thermal expansion of the brass attenuator guide is about 11.6 parts per million (ppm) $/{ }^{\circ} \mathrm{F}$. Thus, for each degree $\mathrm{F}$ increase in ambient temperature from $68^{\circ} \mathrm{F}$, the attenuation rate given in table I must be reduced by $11.6 \mathrm{ppm}$ or $0.000232 \mathrm{~dB} /$ inch. Thus, for an ambient temperature of $72^{\circ} \mathrm{F}$, the attenuation rate would be decreased by a total of $0.000928 \mathrm{~dB} / \mathrm{inch}$. The attenuation rate at $72^{\circ} \mathrm{F}$ is given in table II.

\section{Table II}

Attenuation Rate of Piston Attenuator at Ambient Temperature of 72 degrees $F$.

Frequency of Operation

$\mathrm{MHz}$

55

50

30
Attenuation Rate $\mathrm{DB} /$ Inch

19.99925

19.99907

19.99710

The coefficient of thermal expansion of the lead screw is about $8 \mathrm{ppm} /{ }^{\circ} \mathrm{F}$, which means that the lead of the screw changes by this amount. Thus, an indicated attenuation change on the mechanical readout should be decreased by only the difference between the guide and lead screw expansion coefficients, or $3.6 \mathrm{ppm} /{ }^{\circ} \mathrm{F}$. The lead screw expansion compensates for much of the guide expansion in this case.

The electronic readout derives its two most significant digits from the geared digitizers so thermal expansion of the diffraction grating would have little effect on the over- 
all reading. Therefore, when the electronic readout is used to determine attenuation, the rate must be reduced by the full $11.6 \mathrm{ppm} /{ }^{\circ} \mathrm{F}$ for temperature increases.

\subsection{Summary of Errors}

To summarize, the attenuation rate is as given in table I to an uncertainty of $\pm 0.001 \mathrm{~dB} /$ inch. The uncertainty in measuring displacement is $\pm 0.001 \mathrm{~dB} /$ inch for the electronic readout and $\pm 0.0024 \mathrm{~dB} /$ inch for the mechanical readout. Thus, the total uncertainty in producing a $20 \mathrm{~dB}$ attenuation change at an ambient temperature of $68^{\circ} \mathrm{F}$ is as follows:

Electronic Readout ... . $\pm 0.0019 \mathrm{~dB}$
Mechanical Readout ... $\pm 0.0033 \mathrm{~dB}$.

\section{SUMMARY}

An accurate waveguide-below-cutoff (piston) attenuator has been described. The attenuator is adjusted to operate at a frequency of $50 \mathrm{MHz}$ but the guide diameter was calculated to give an attenuation rate of $20 \mathrm{~dB} /$ inch at $55 \mathrm{MHz}$. The actual attenuation rate for the final guide diameter has been given for 55, 50, and $30 \mathrm{MHz}$. Sources of error in the attenuation rate and displacement readouts have been evaluated. The effects of ambient temperature changes have been analyzed and sufficient data given to enable the user to make accurate corrections for these effects.

The results show that at $68^{\circ} \mathrm{F}$, the attenuation rate for 55 and $50 \mathrm{MHz}$ may be considered to be exactly $20 \mathrm{~dB} /$ inch.

It is the author's opinion that this attenuator could be operated at $55 \mathrm{MHz}$ without readjusting the impedance matching networks and get no adverse effects other than having large reflections in the system and mismatch losses of up to about $6 \mathrm{~dB}$. 
This discussion has covered the operation of a piston attenuator and sources of errors associated with it. In order to use this attenuator, it must be inserted into a system containing a minimum of an rf signal source, an rf detector, a device under test, and interconnecting cables. This introduces additional sources of errors, such as rf source instability (amplitude or frequency), detector instability and noise, rf leakage, and movement of flexible coaxial cables during measurement. Discussion of the measurement system is beyond the scope of this paper but is covered in references [1] and [2].

\section{ACKNOWLEDGMENTS}

This attenuator was built for the Jet Propulsion Laboratory under P.O. No. FY-567495.

The author would like to acknowledge the assistance of the following persons: Victor Lecinski for an excellent job of mechanical design and layout, especially in locating the electronic displacement sensor assembly before the unit was received; and Walter $K$. Stephenson for a superior job of fabrication of the attenuator.

\section{REFERENCES}

1. D. Russell and W. Larson, RF Attenuation, Proceedings of the IEEE, Vol. 55, No. 6, June 1967, 942-959.

2. Robert W. Beatty, Microwave Attenuation Measurements and Standards, NBS Monograph 97, April 1967.

3. Clarence C. Cook and C. McKay Allred, An Excitation System for Piston Attenuators, IEEE Transactions on Instrumentation and Measurement, Vol. IM-20, No. 1, February 1971, 10-16. 
10. PARTS LIST

This list includes only the critical parts necessary for the fabrication of this attenuator. These are identified by the corresponding part numbers in Figures 4 (a) through 4 (s). Non-critical stock items, such as machine screws, are not given here.

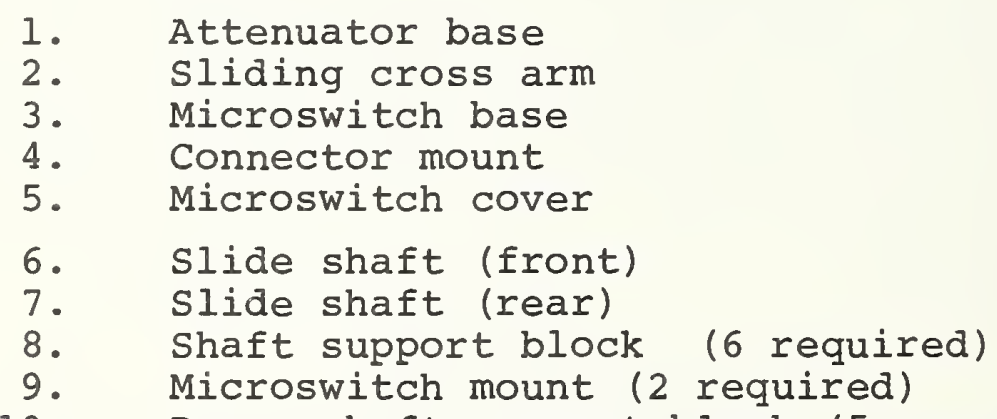

1. Attenuator base

2. Sliding cross arm

3. Microswitch base

4. Connector mount

5. Microswitch cover

6. Slide shaft (front)

7. Slide shaft (rear)

8. Shaft support block (6 required)

9. Microswitch mount (2 required)

10. Base, shaft support block (5 required)

11. Base, shaft support block

12. Mode filter

13. Input connector

14. Capacitor mount, exciter

15. Input connector mount

16. Exciter housing

17,18. Insulating mount, series capacitor (exciter)

19. Coil mount, exciter

20. Coil spacer, exciter (2 required)

21. Coil form, exciter

22. Circular waveguide

23. Locking nut, exciter

24. Coil form, receiver

25. Cover

26. Capacitor housing

27. Piston guide

28. Capacitor mount, receiver

29,30. Insulating mount, series capacitor, receiver 
31. Lead screw

32. Coaxial cable

33. Retainer nut

34. Wiper (2 required)

35. Drive Nut

36,37. Helix gear pair

38. Anti-backlash nut

39. Drive shaft

40. Drive shaft spacer

41. Drive shaft bushing

42. Dial

43. Knob bushing

44,45 . Bevel gear pair

46. Manual control knob

47. Waveguide support

48. Bearing housing

49. Helix gear housing

50. Bearing retainer

51. Preload ring (2 required)

52. Bearing spacer

53. Counter mount plate

54. Counter drive shaft support

55. Helix gear key

56. Bevel gear key

57. Counter

58. Counter drive shaft

59. Drive motor

60. Front panel mounting spacer (2 required)

61. Coiled semi-rigid coaxial cable

62. Input and output connector mount

63. Coaxial coil support

64. Coaxial coil end mount

65. Mount, shaft support block (5 required)

66. Mount, shaft support block

67. Front panel

68. Attenuator chassis

69. Chassis rear panel

70. Chassis corner mount

71. Chassis top panel

72. Attenuator base cushion ( 8 required) 


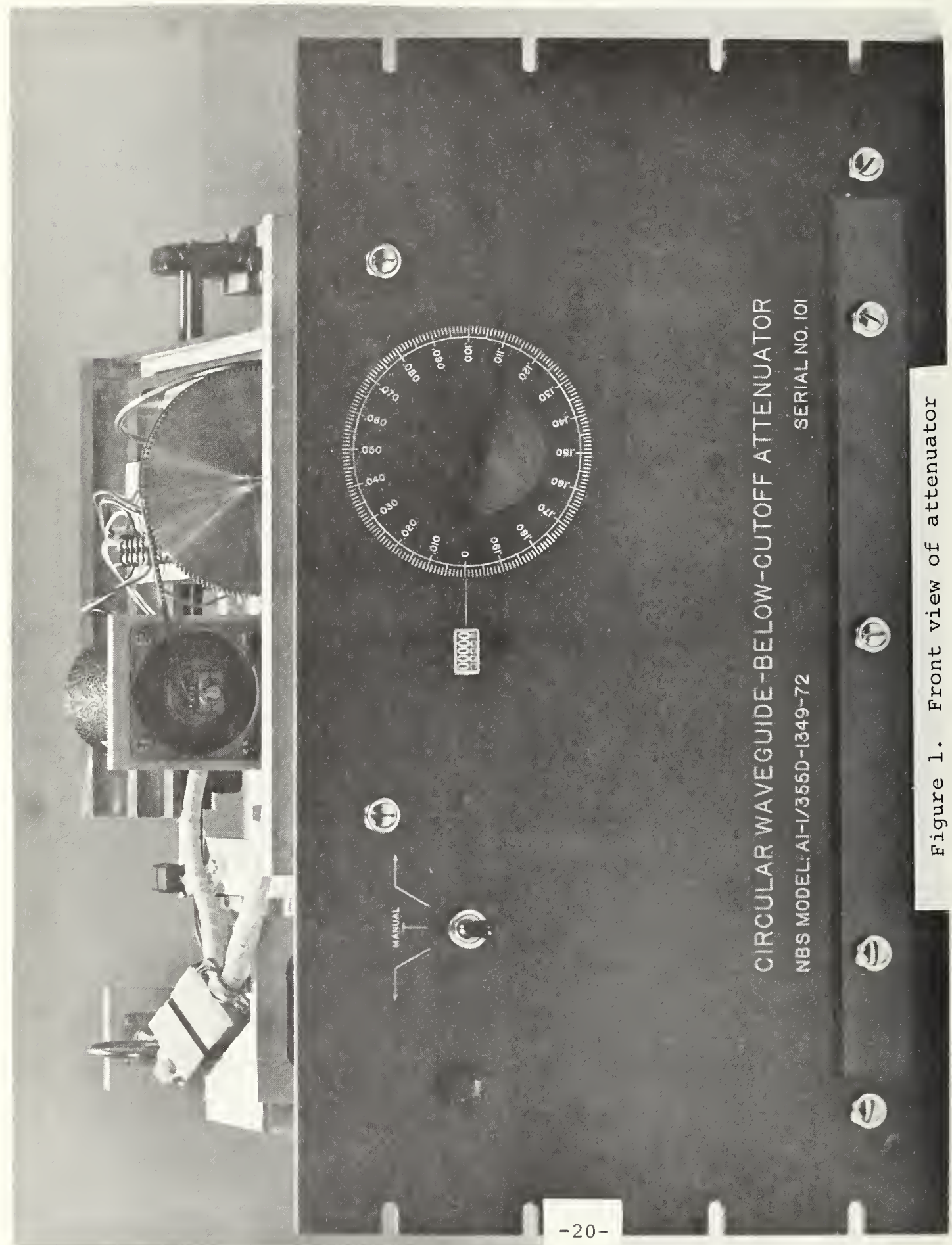




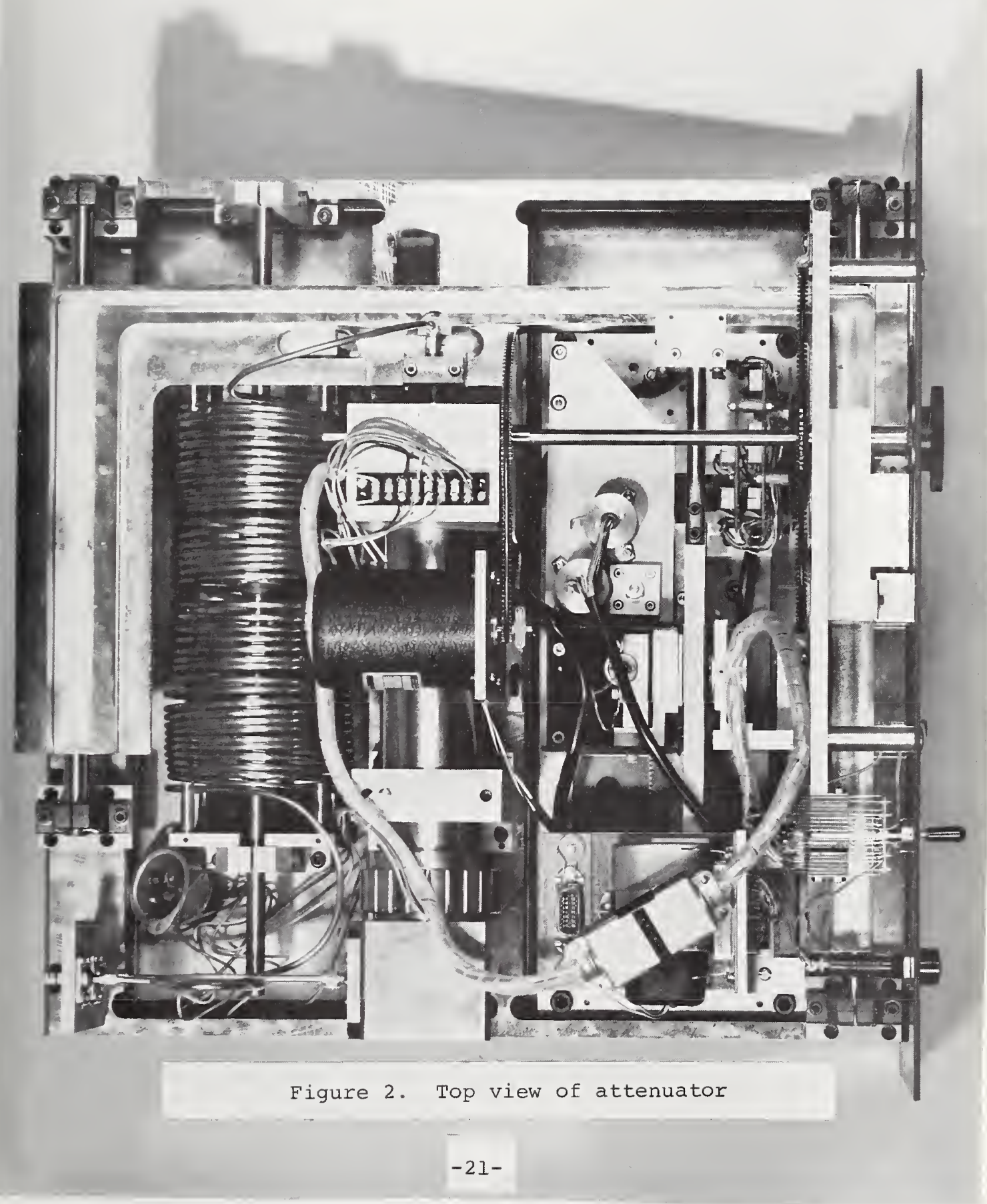




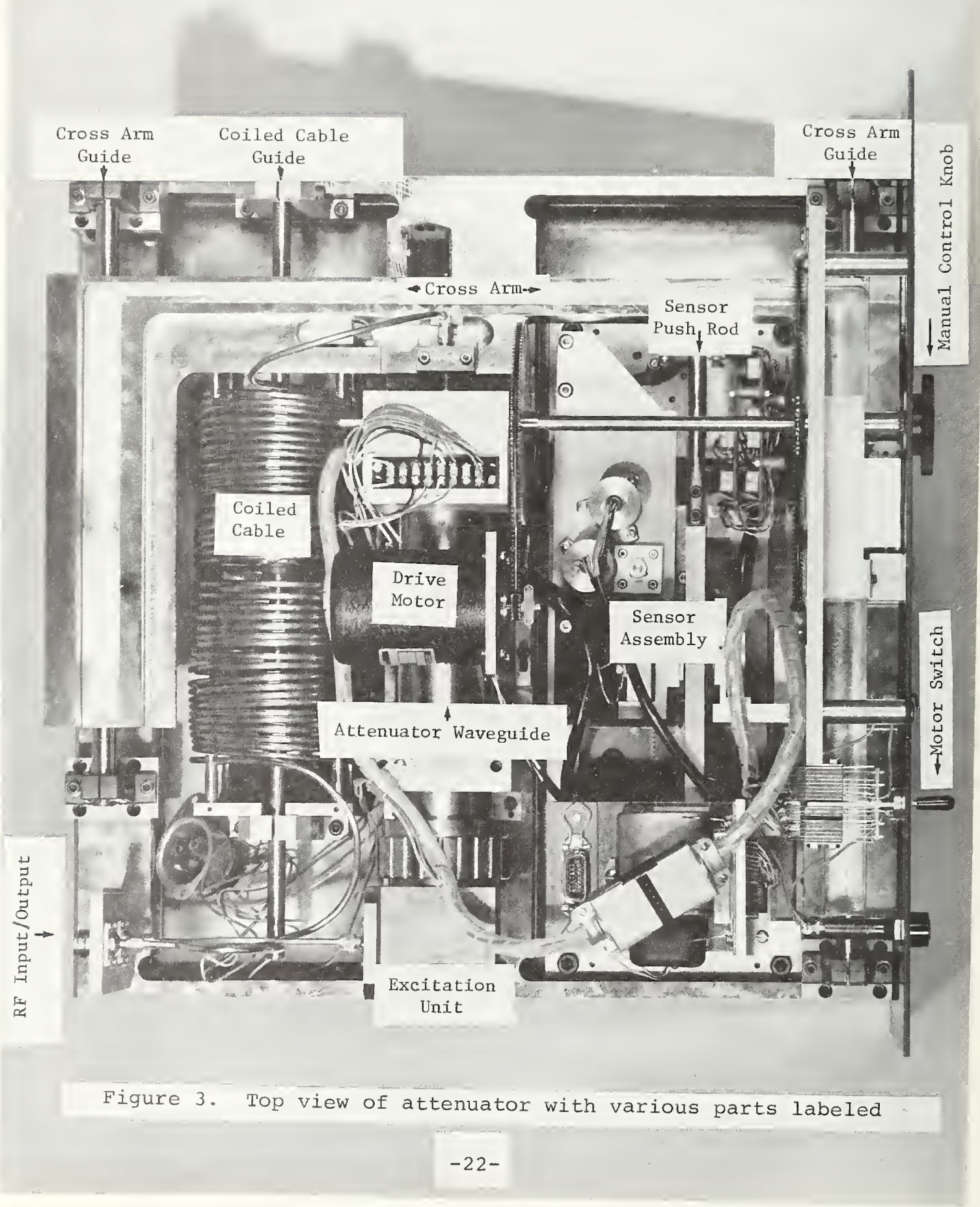




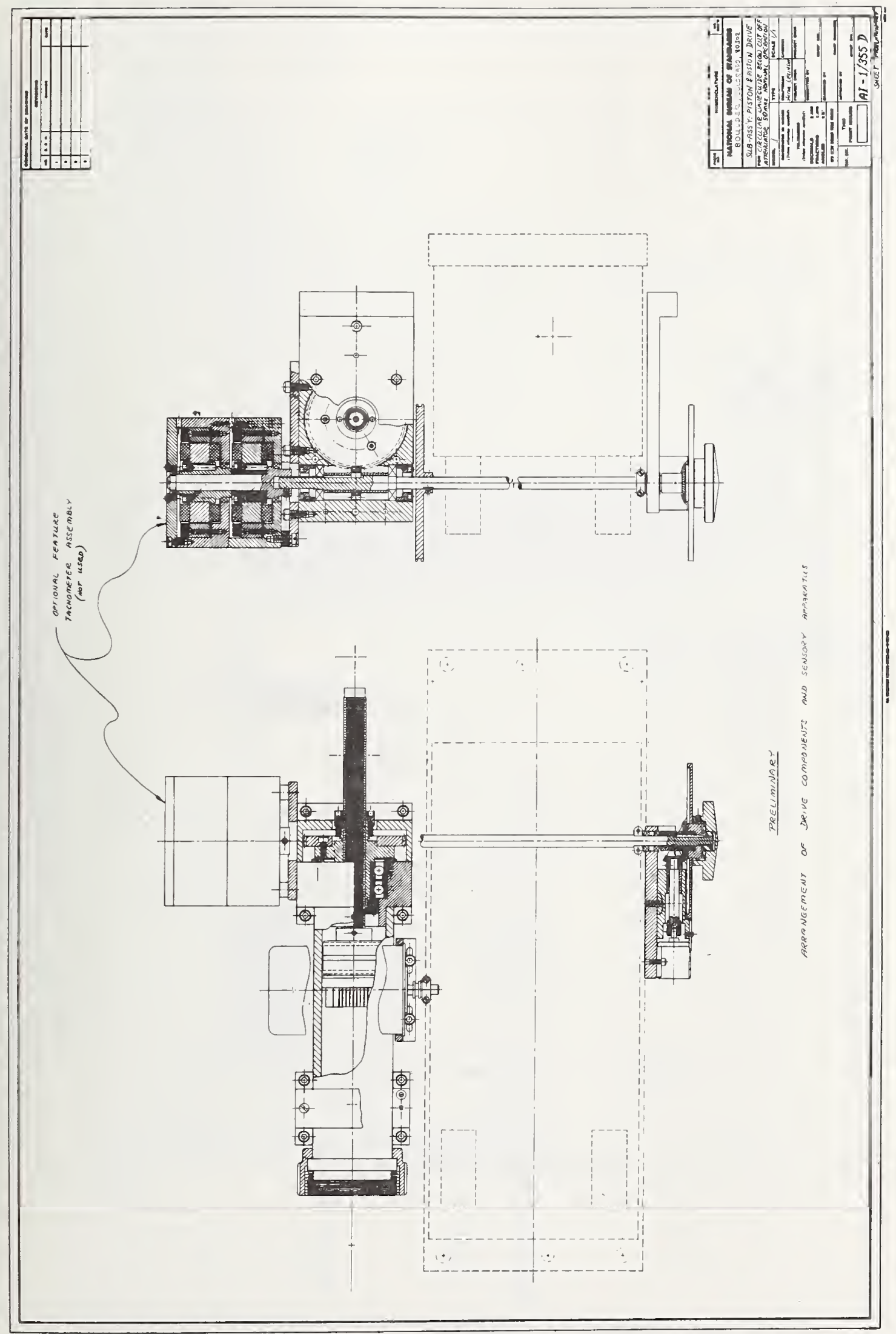




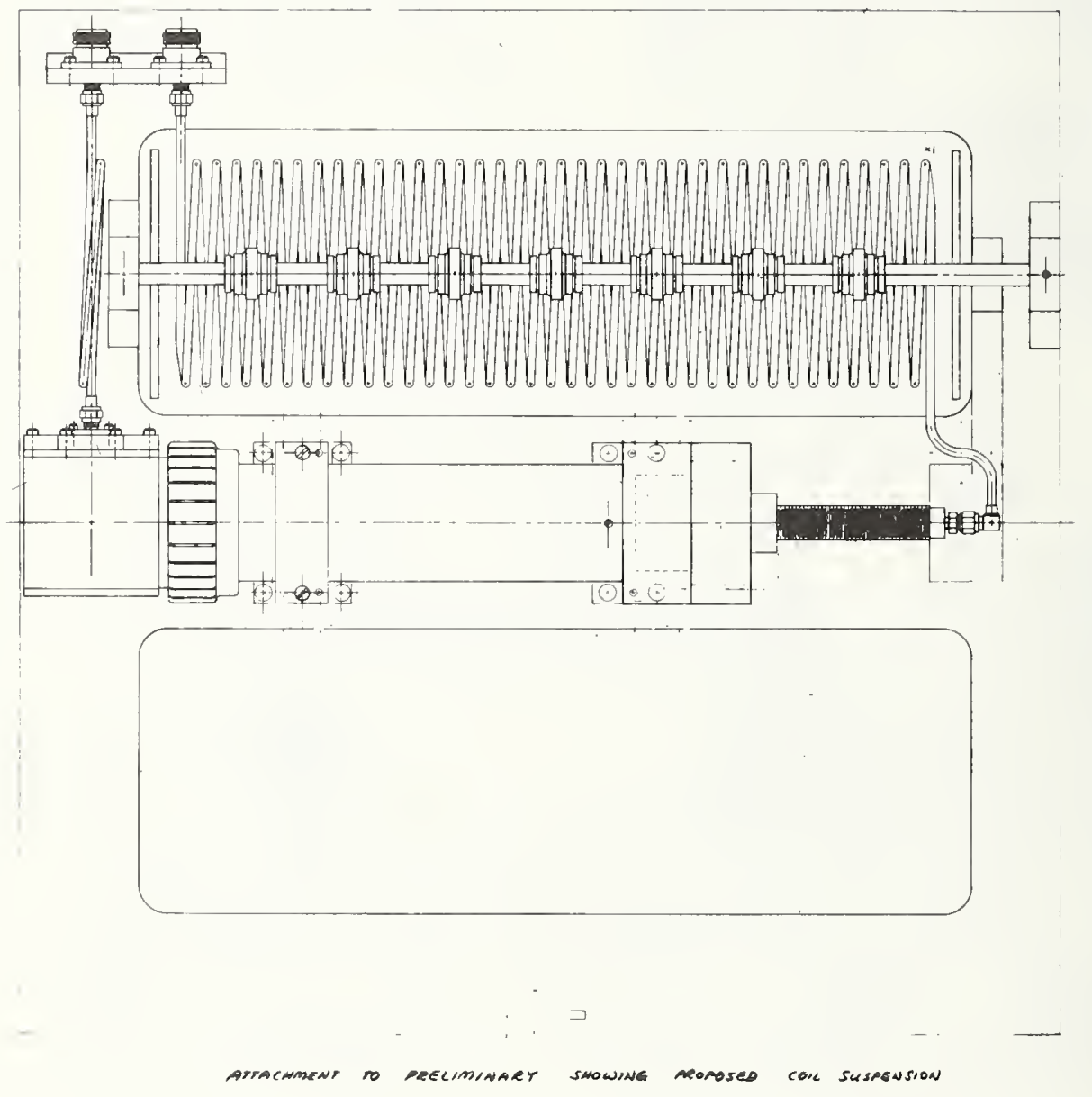

Figure 4 (b) 


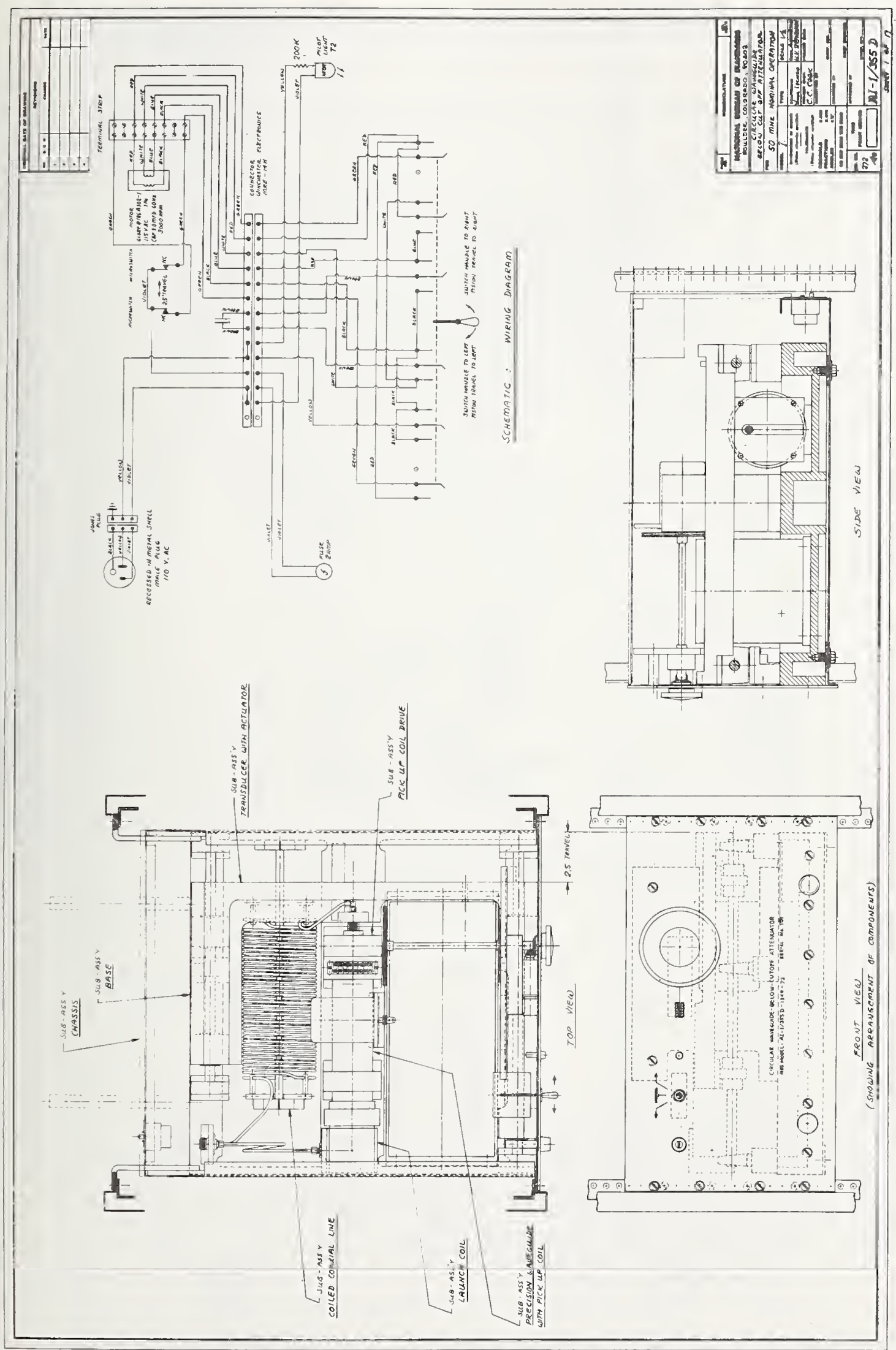




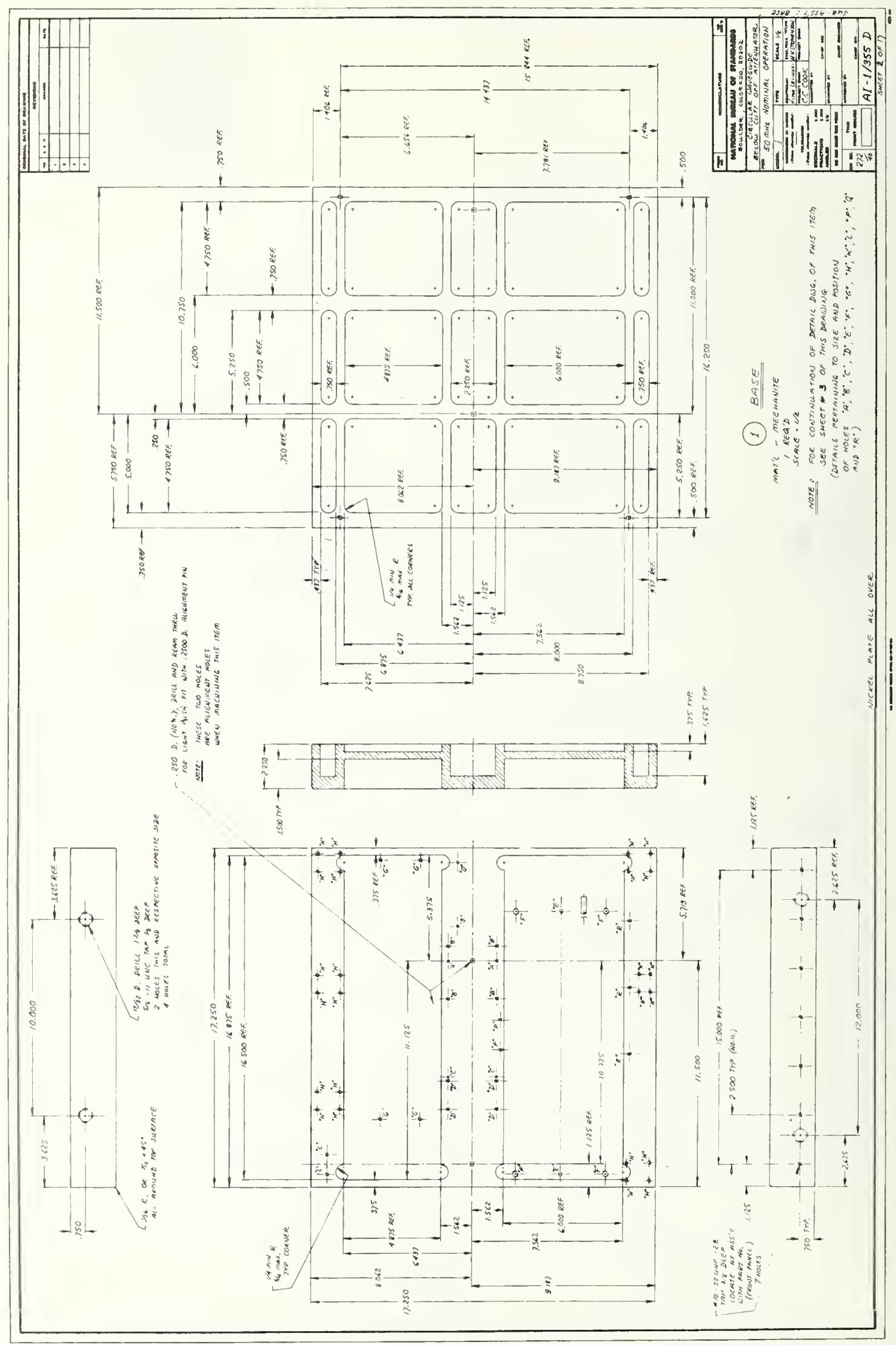




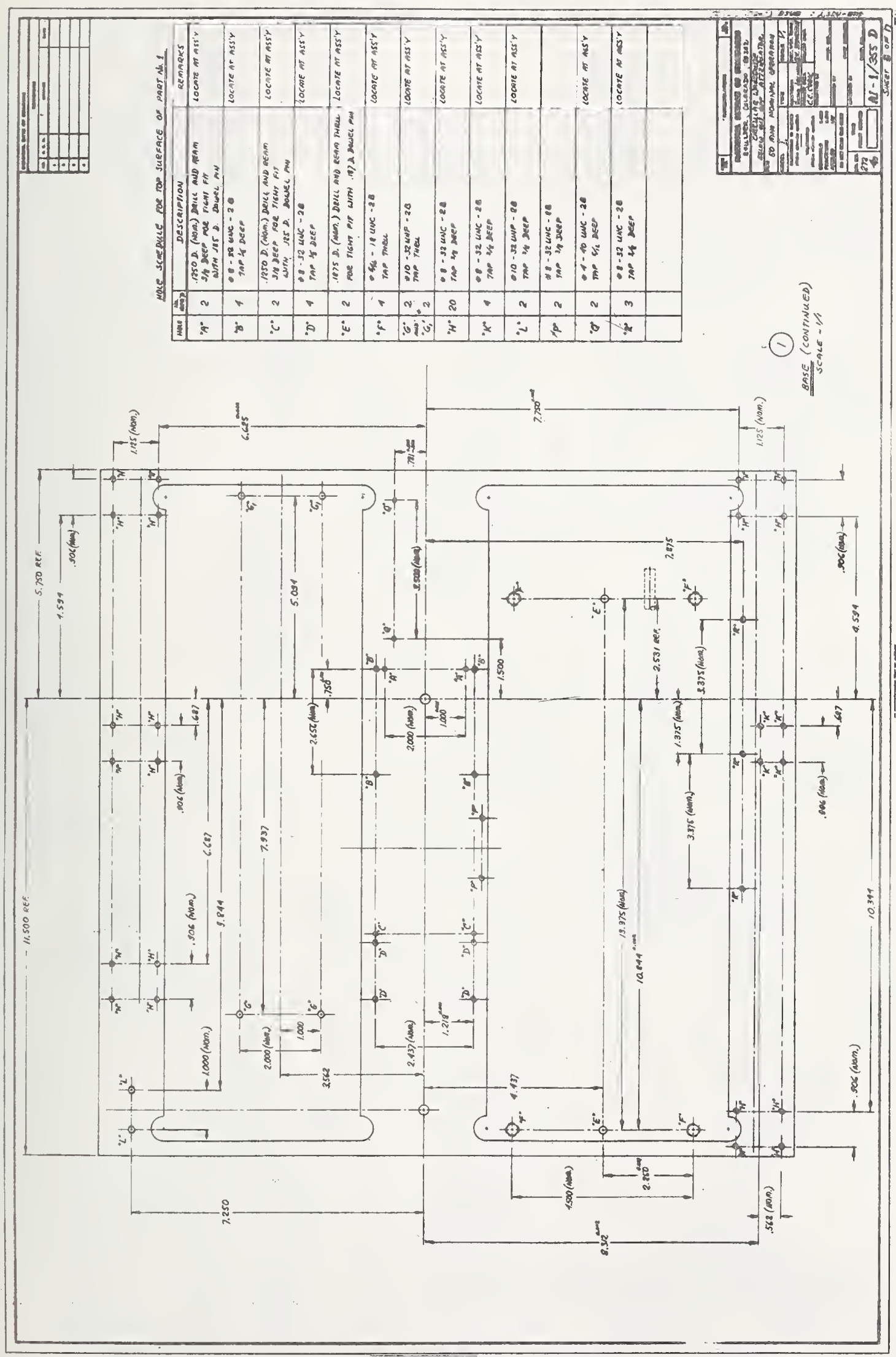




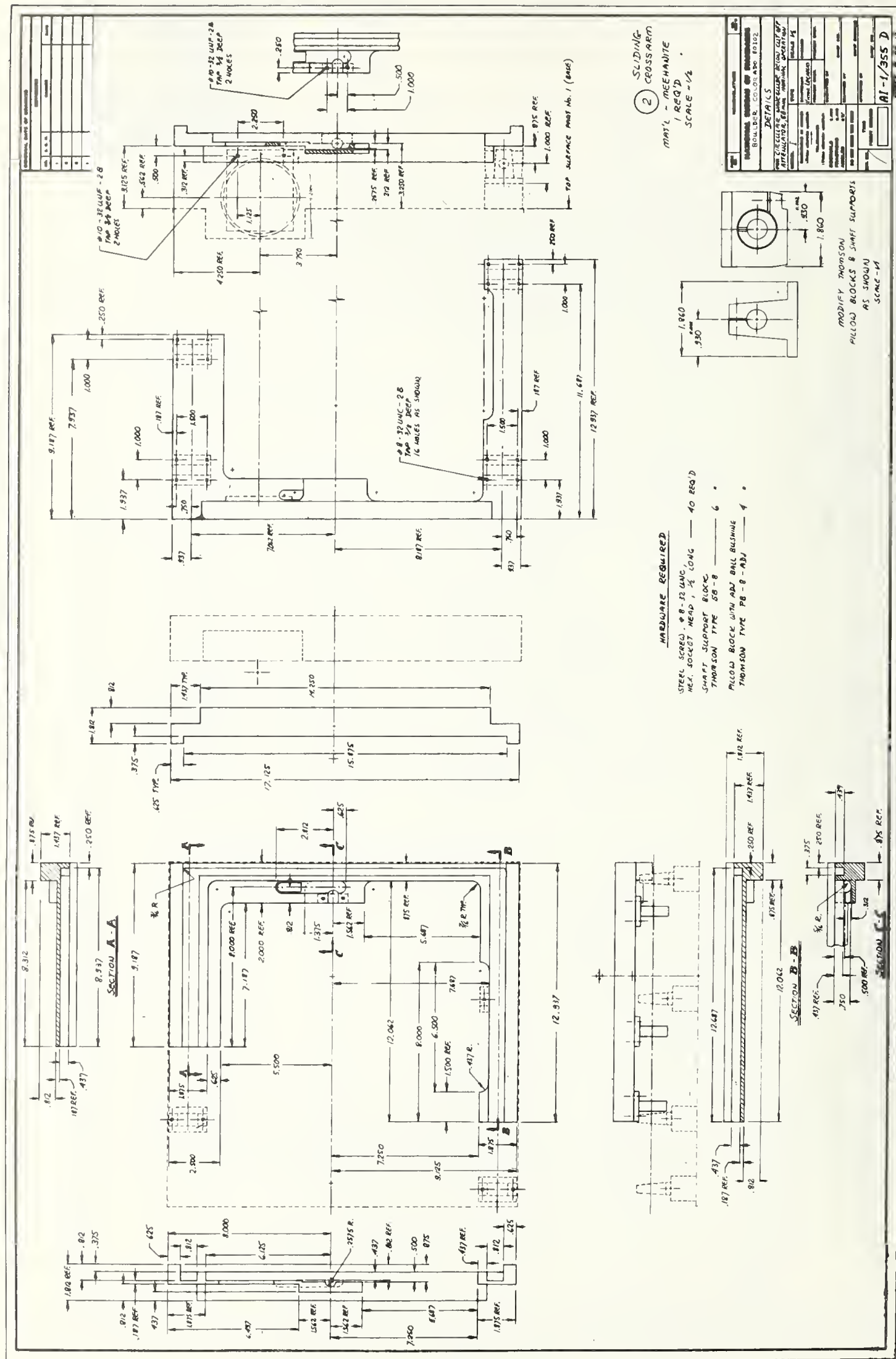




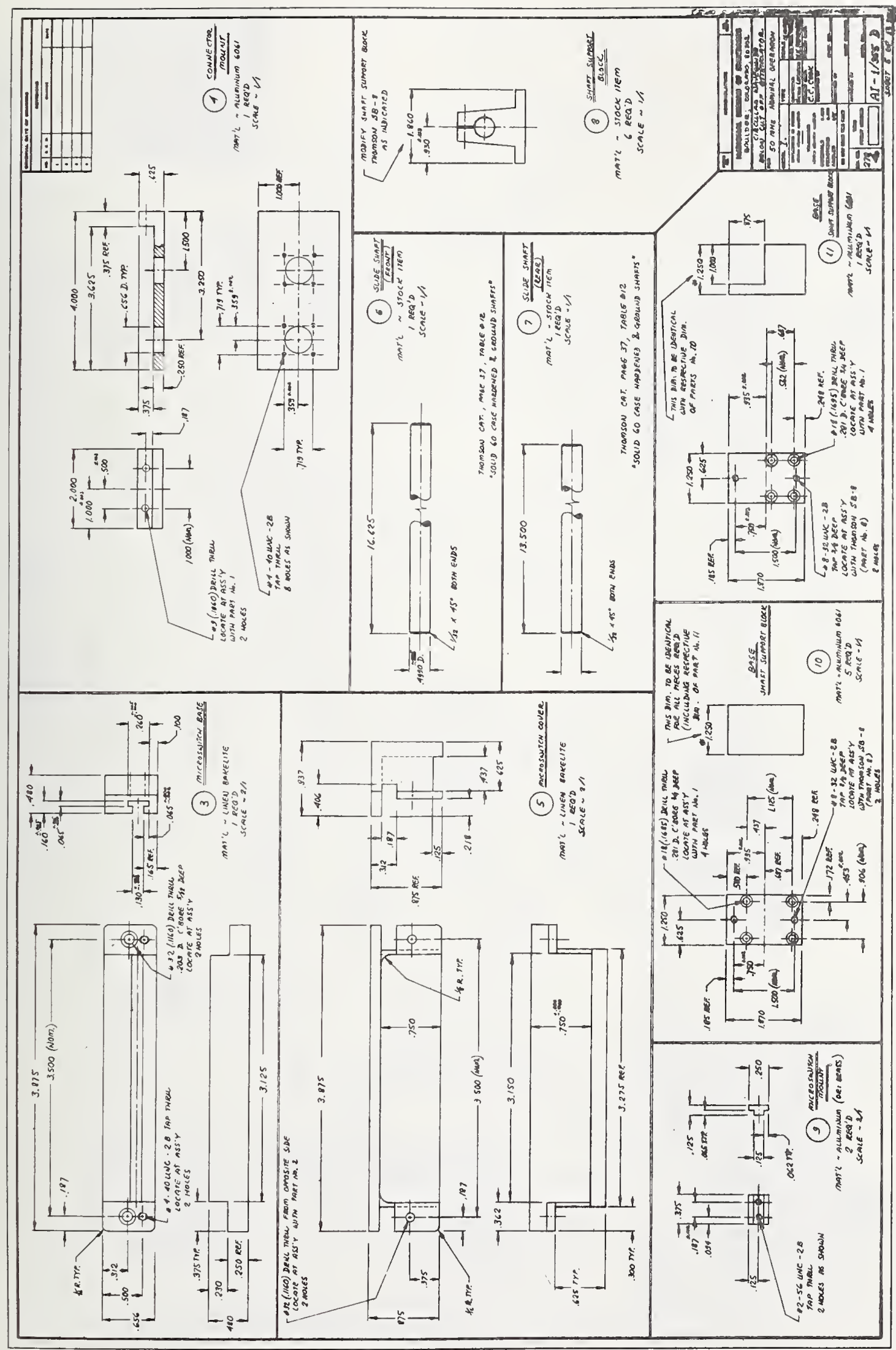

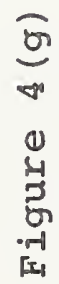




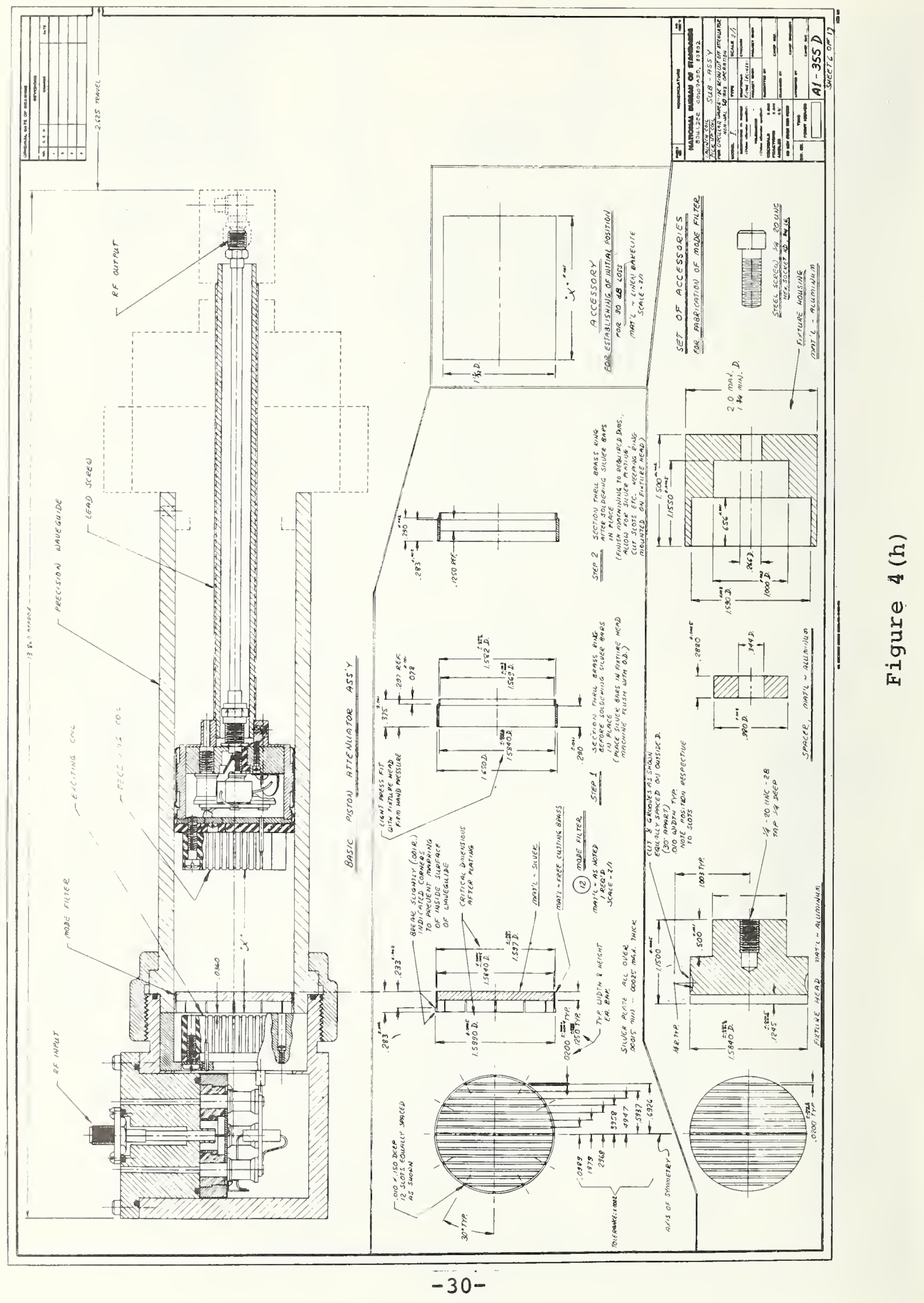




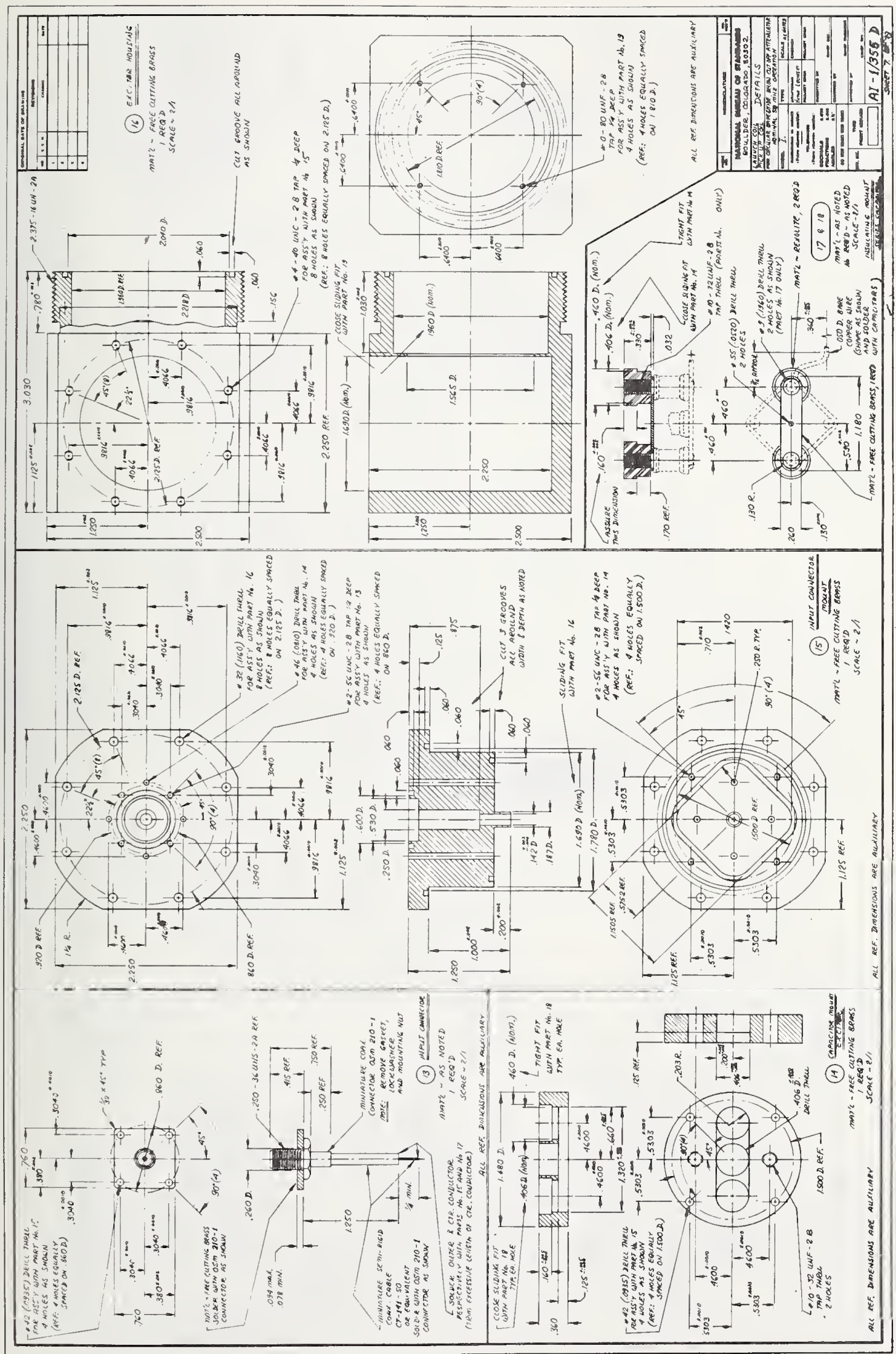

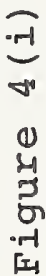




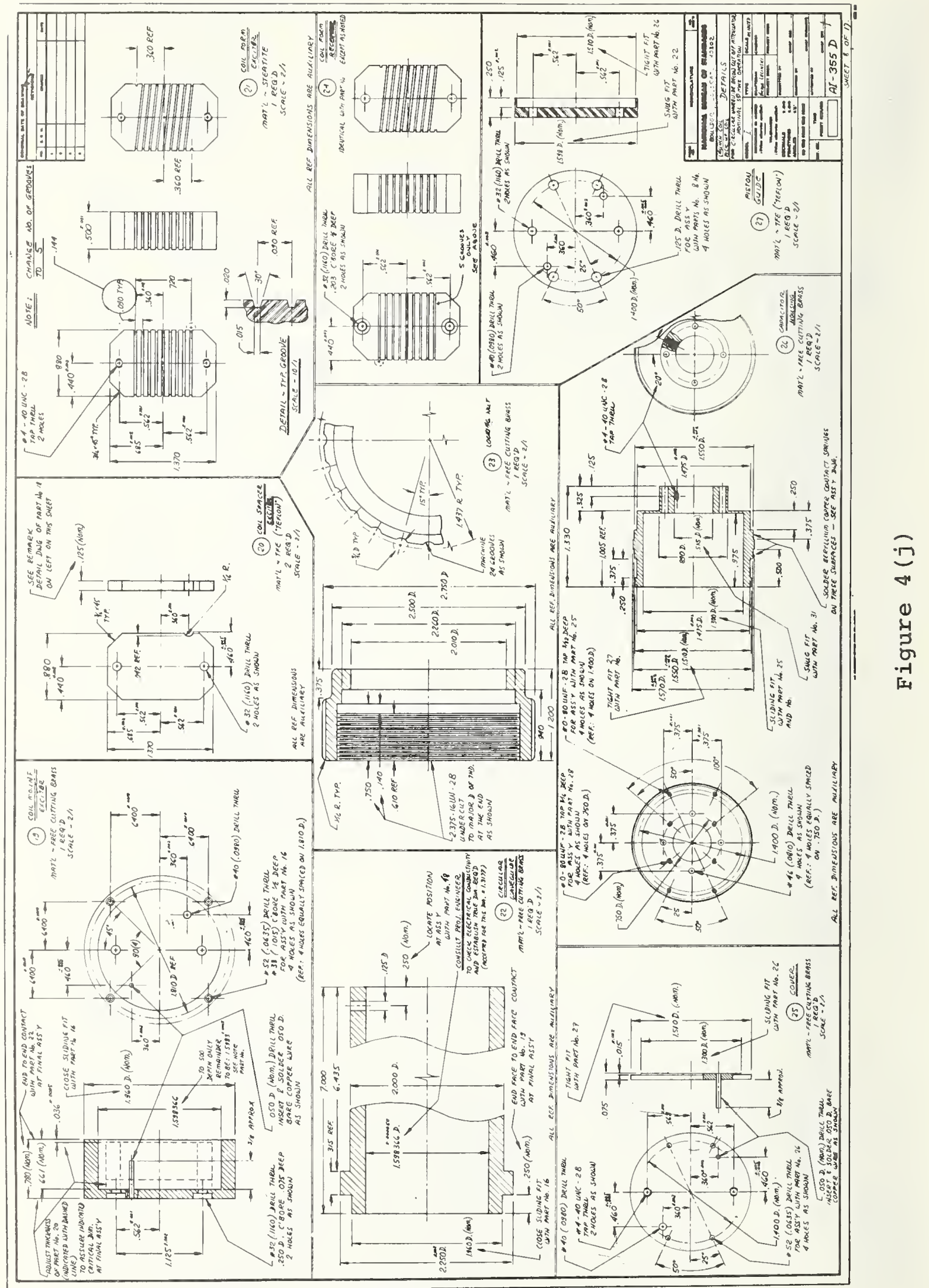




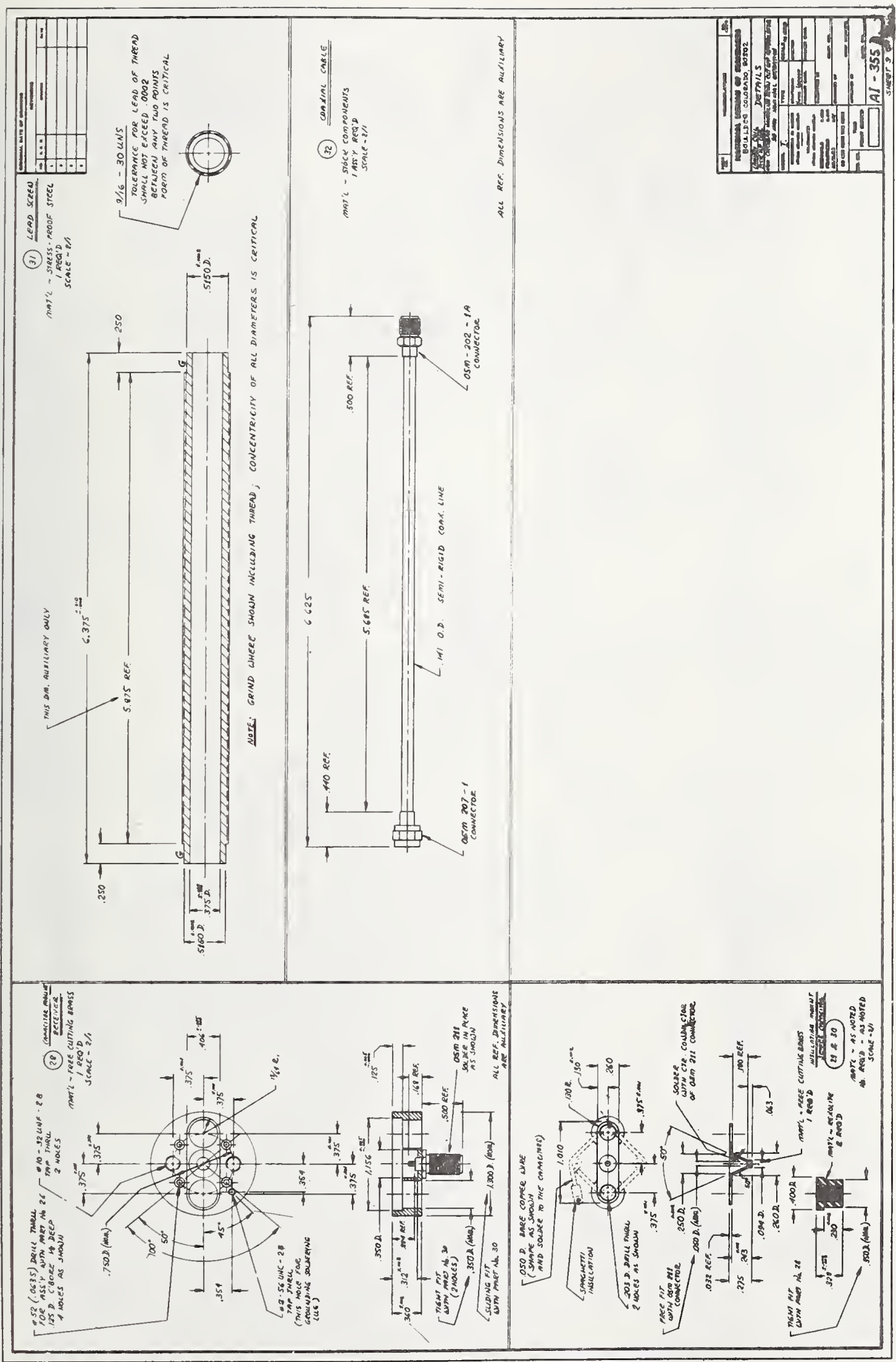

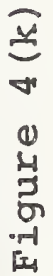




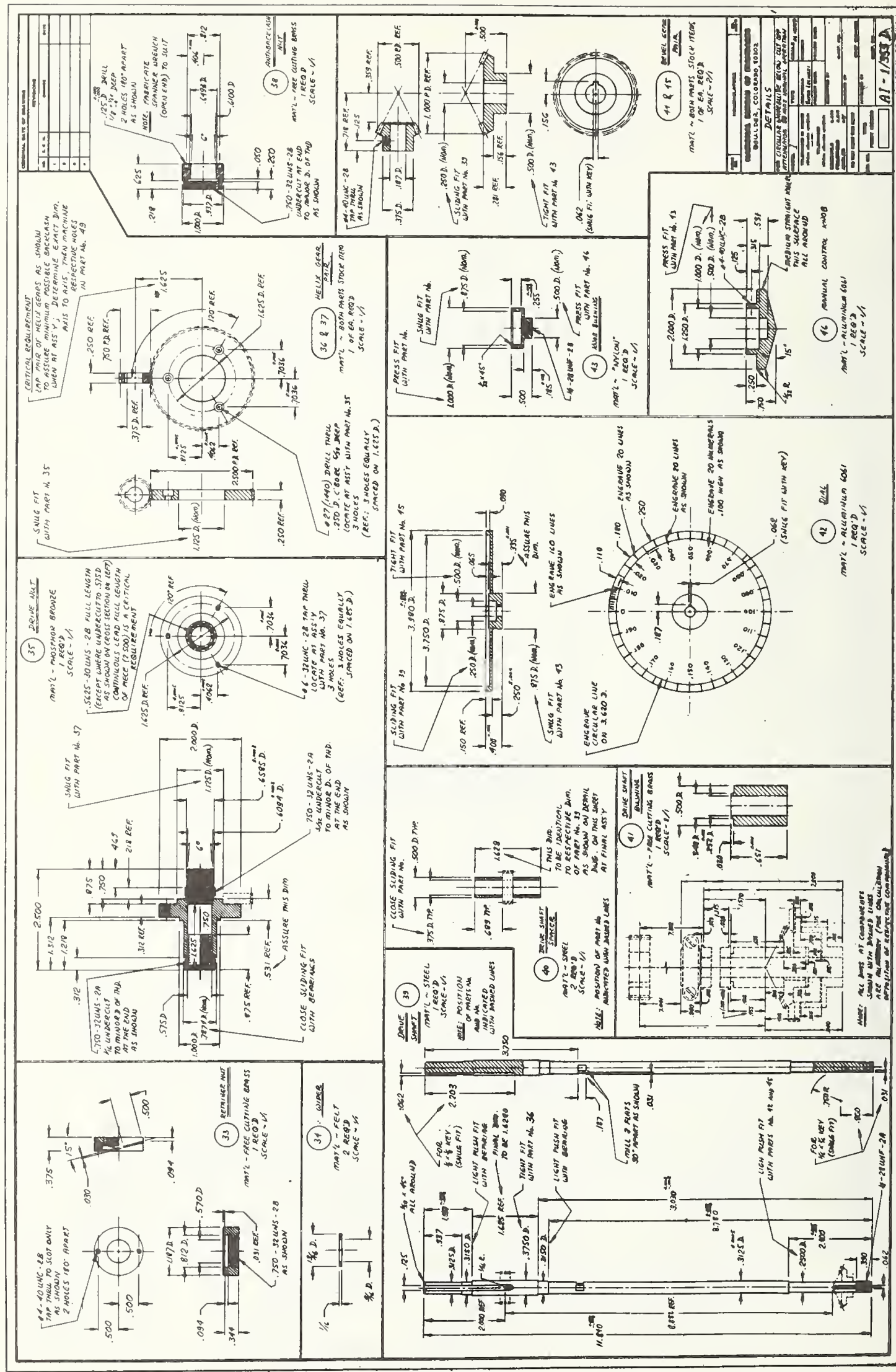




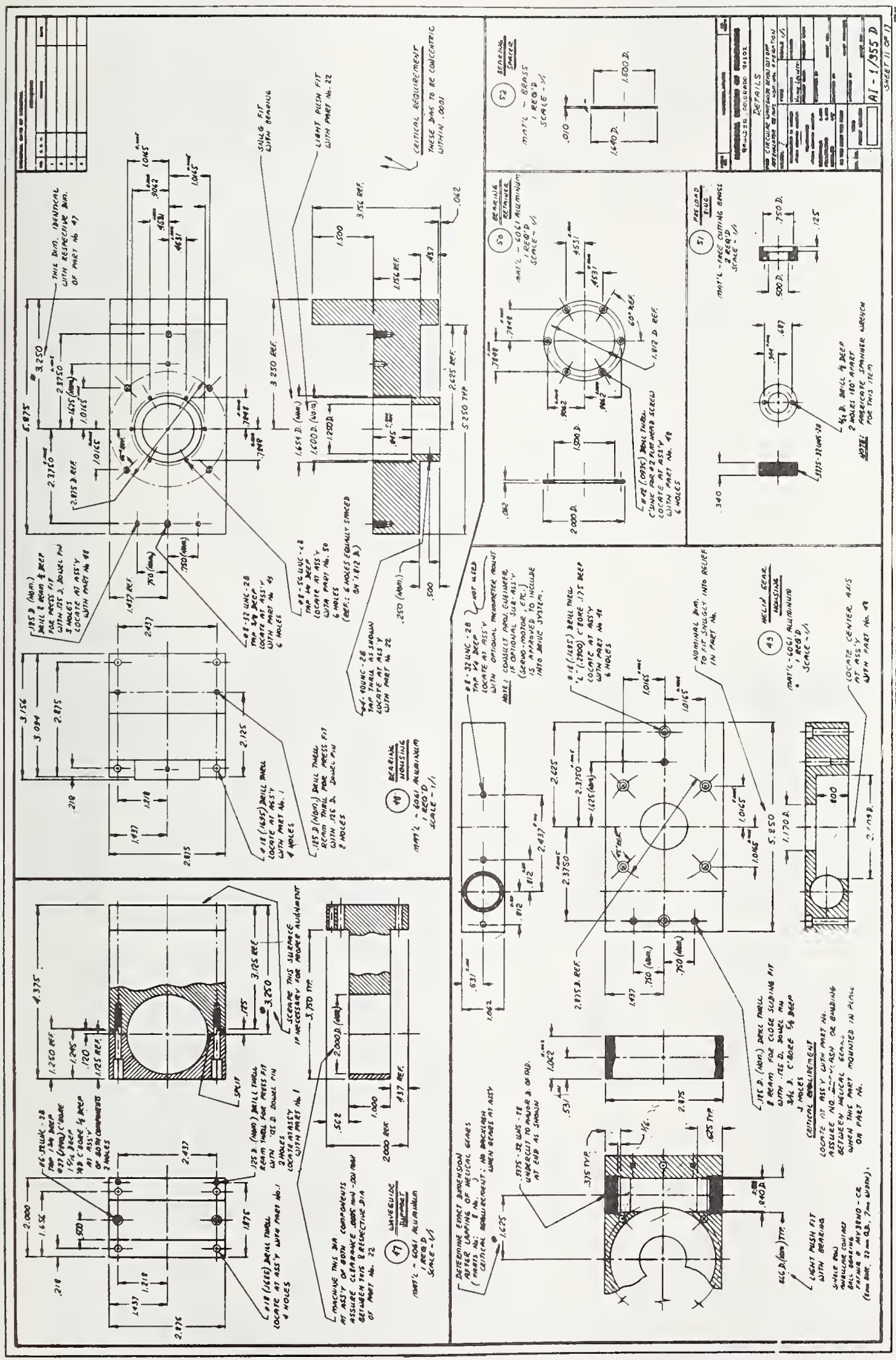




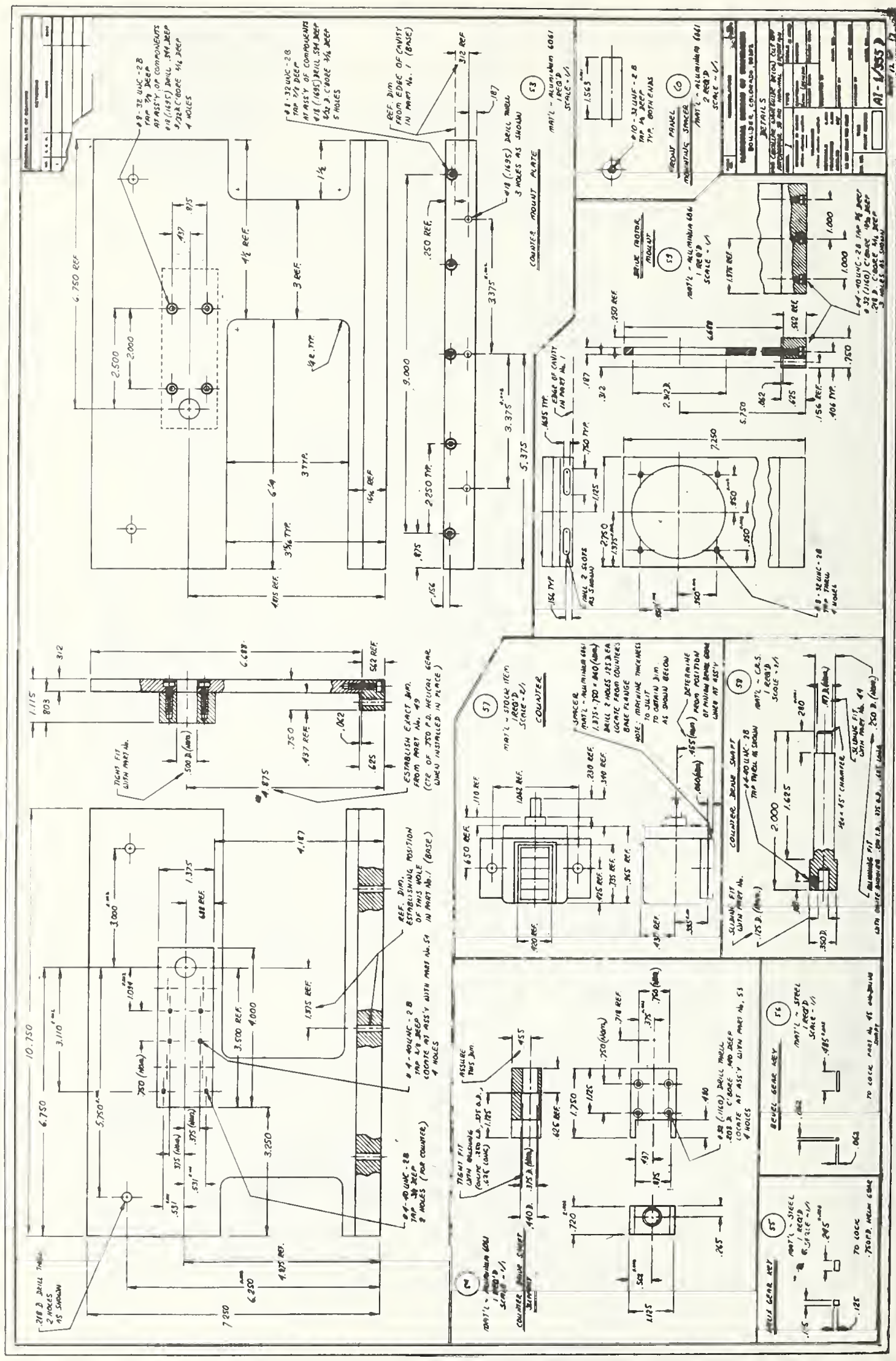




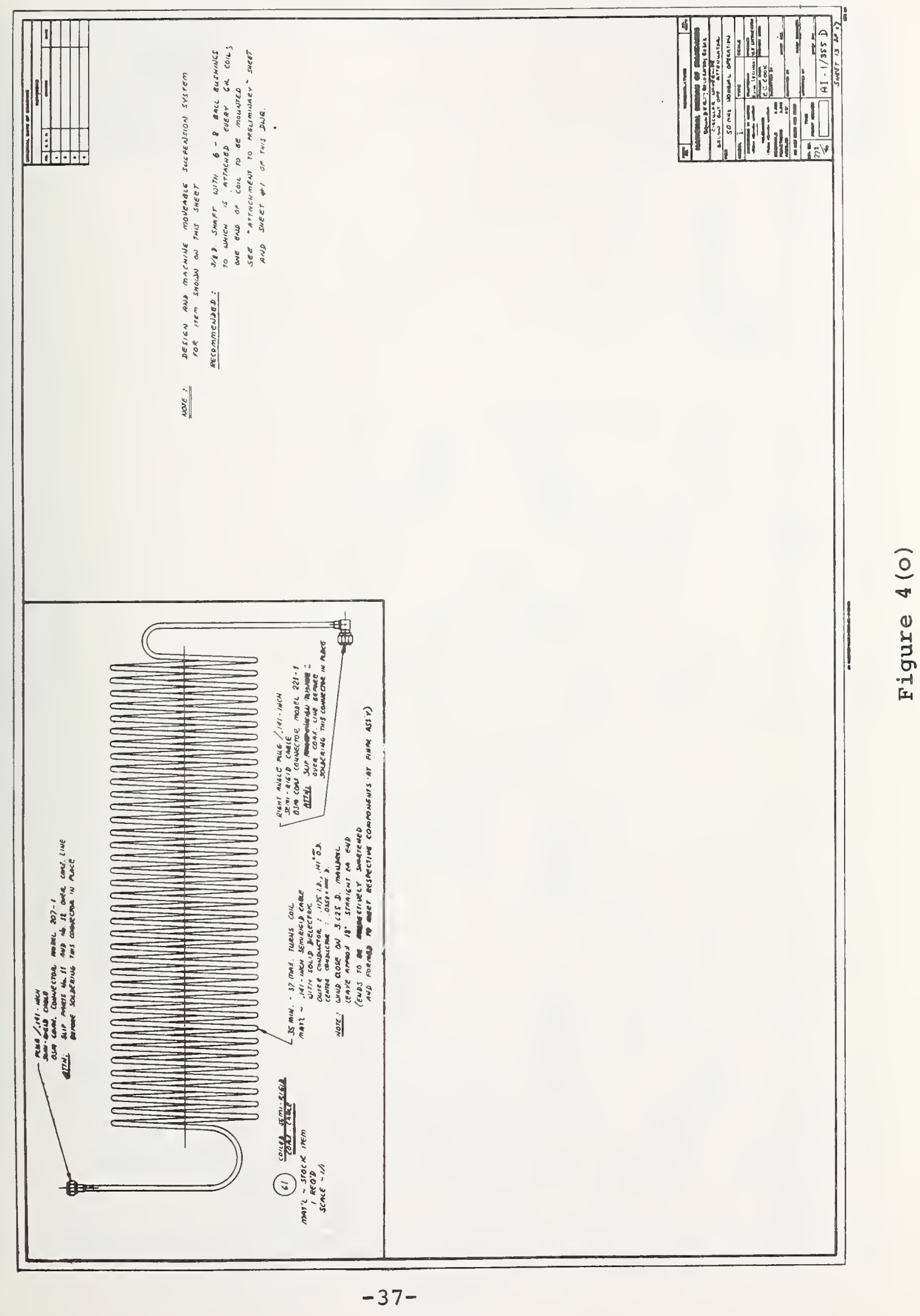




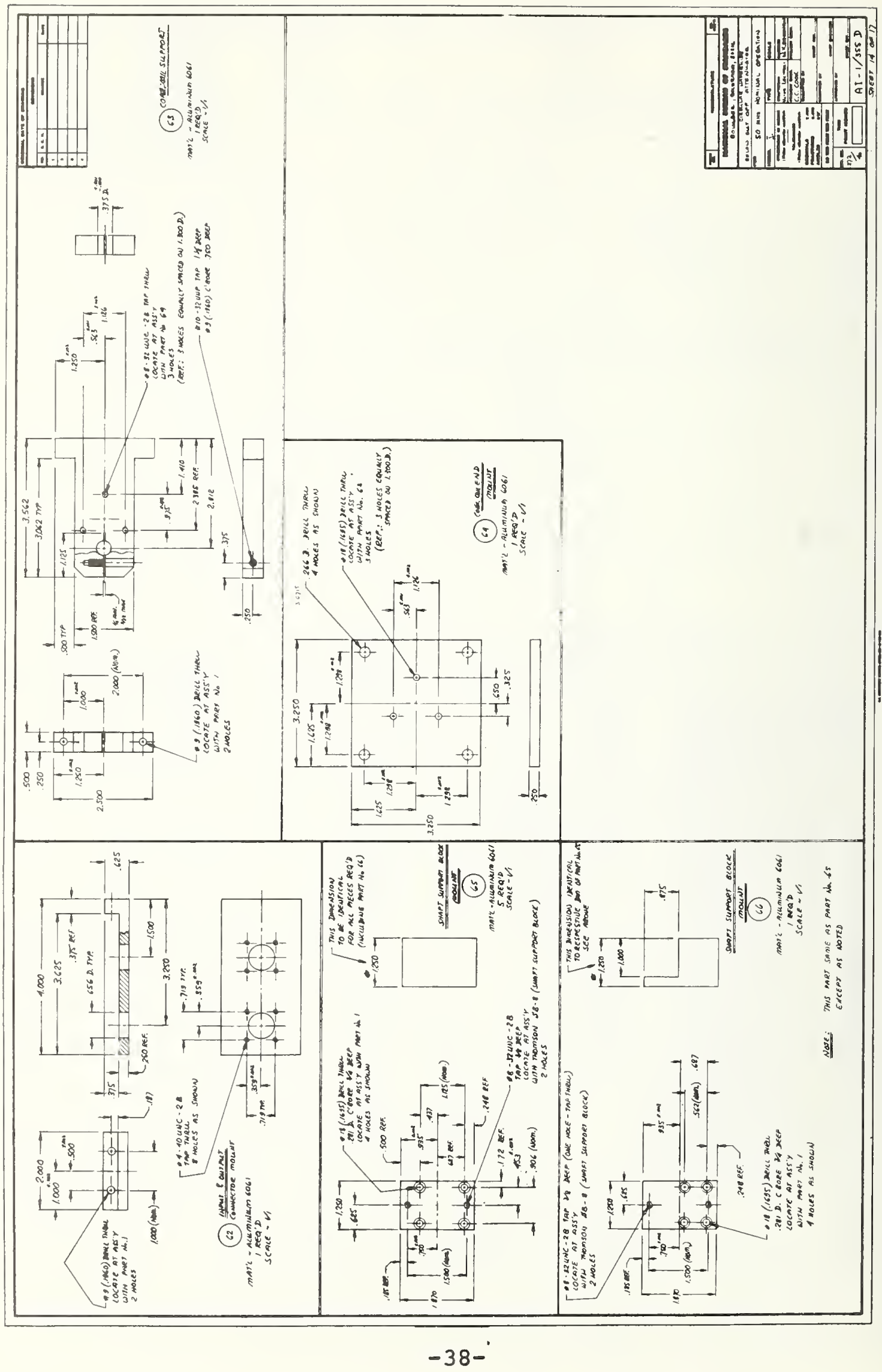

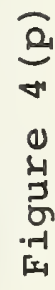




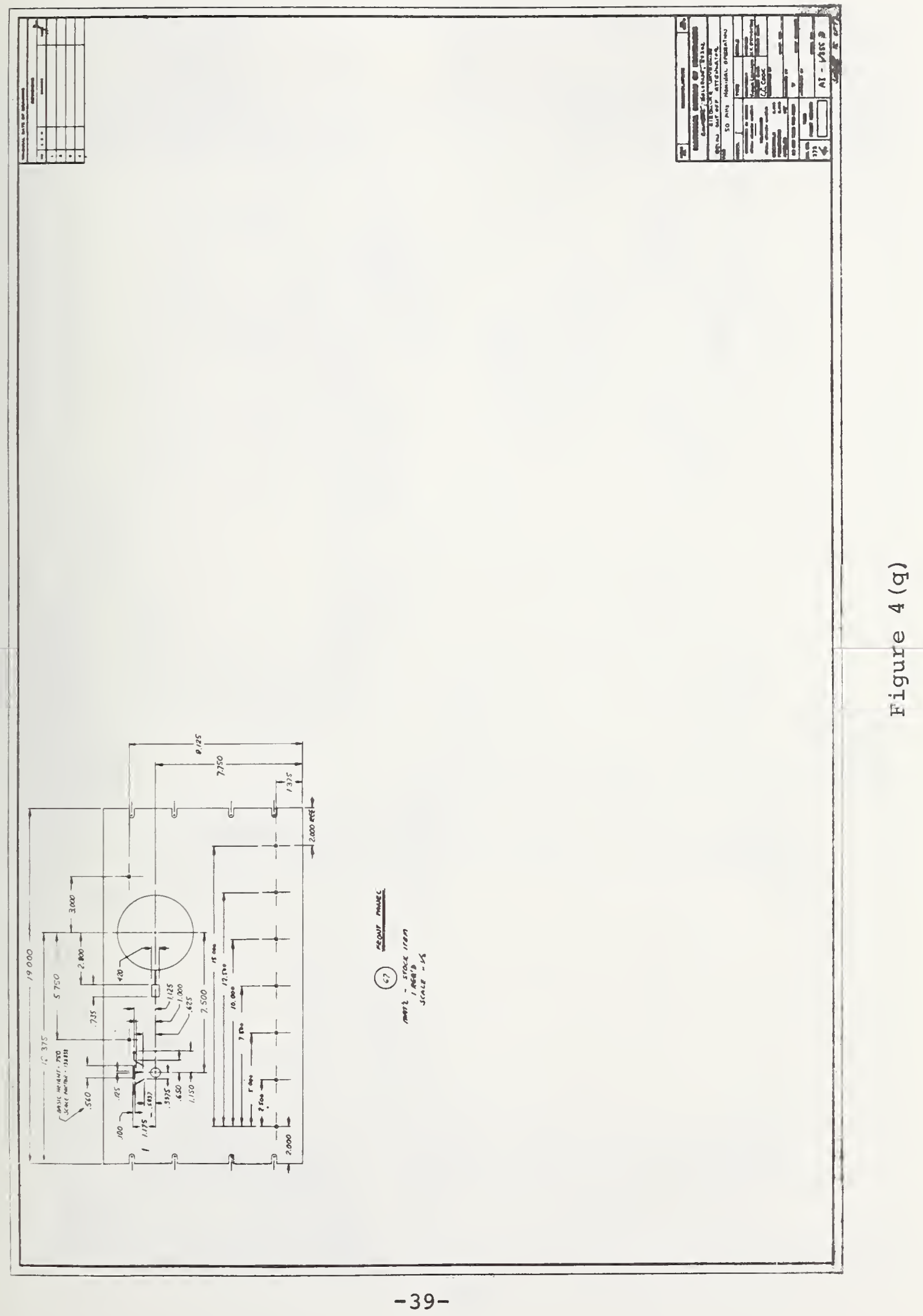




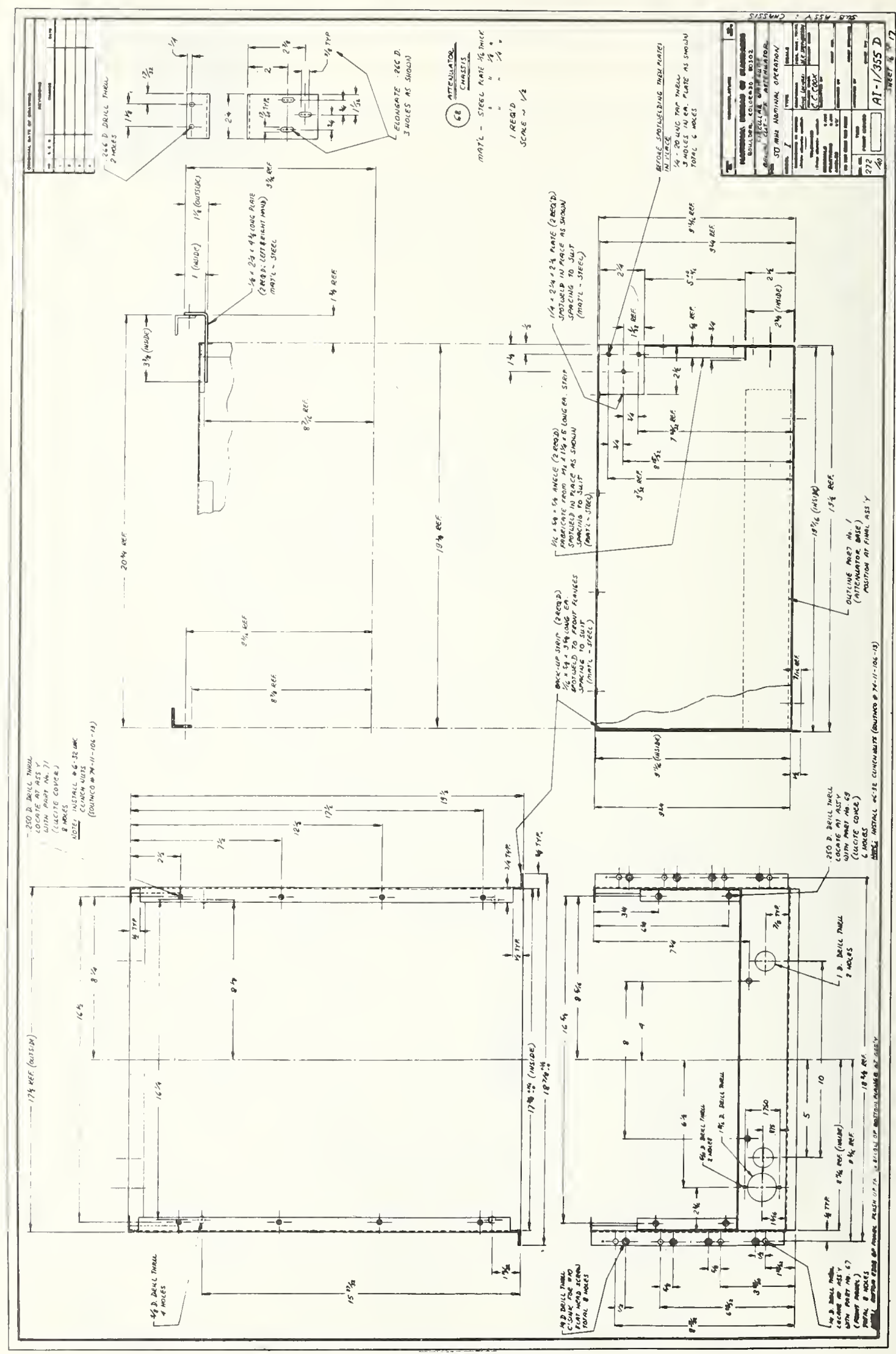

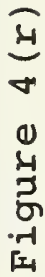




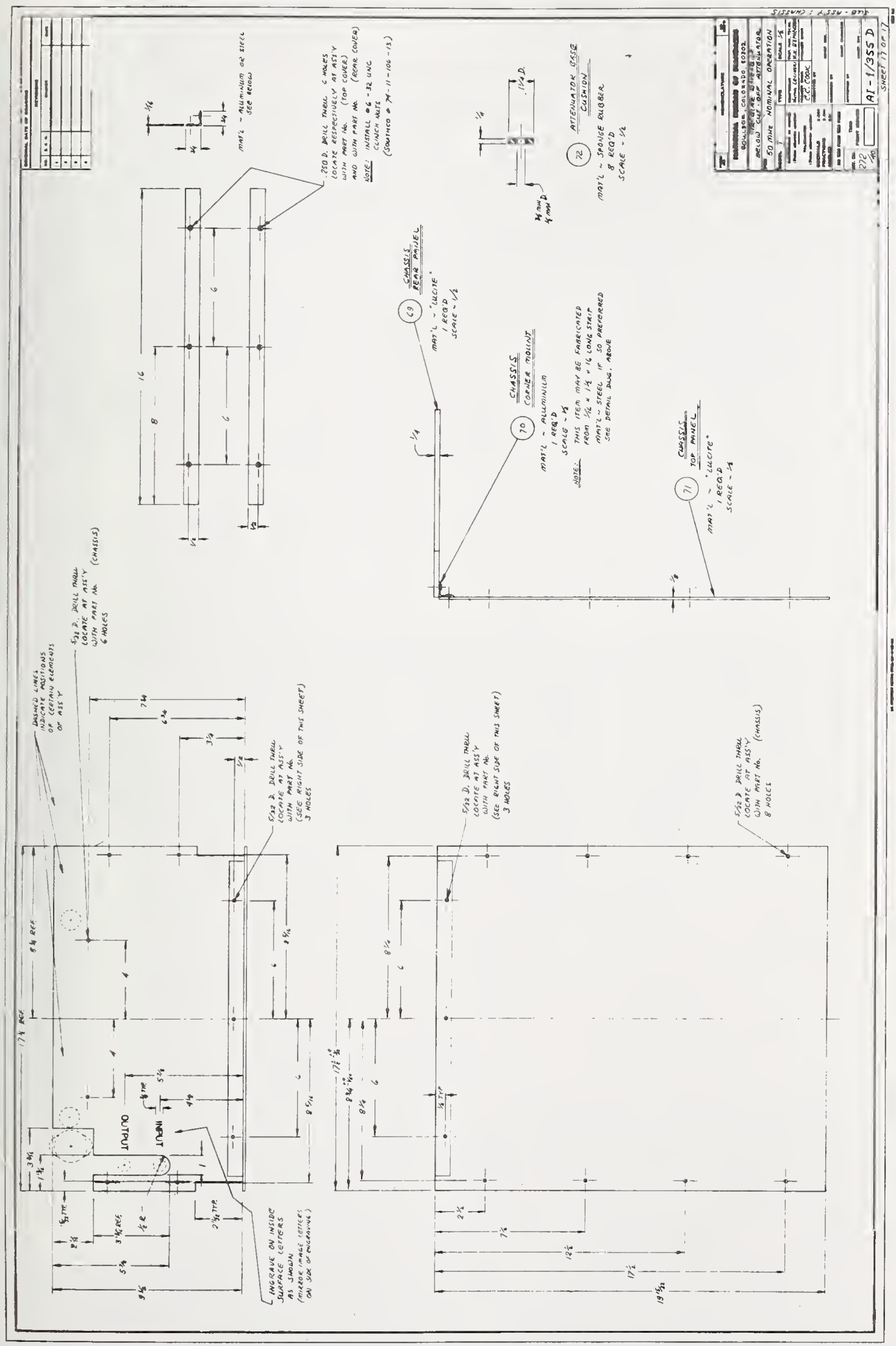




\begin{tabular}{|c|c|c|c|}
\hline $\begin{array}{l}\text { U.S. DEPT. OF COMM. } \\
\text { BIBLIOGRAPHIC DATA } \\
\text { SHEET }\end{array}$ & $\begin{array}{l}\text { 1. PUBLICATION OR REPORT NO. } \\
\text { NBSIR } 74-394\end{array}$ & $\begin{array}{l}\text { 2. Gov't Accession } \\
\text { No. }\end{array}$ & 3. Recipient's Accession No. \\
\hline \multicolumn{3}{|c|}{$\begin{array}{l}\text { 4. TITLE AND SUBTITLE } \\
\qquad \begin{array}{l}\text { A Rack-Mounted Precision Waveguide-Below-Cutoff } \\
\text { Attenuator with an Absolute Electronic Readout }\end{array}\end{array}$} & $\begin{array}{l}\text { 5. Publication Date } \\
\text { November } 1974 \\
\text { 6. Performing Or ganization Code }\end{array}$ \\
\hline \multicolumn{3}{|c|}{$\begin{array}{l}\text { 7. AUTHOR(S) } \\
\text { Clarence C. Cook }\end{array}$} & 8. Performing Organization \\
\hline \multicolumn{3}{|c|}{$\begin{array}{l}\text { 9. PERF ORMING ORGANIZATION NAME AND ADDRESS } \\
\text { NATIONAL BUREAU OF STANDARDS } \\
\text { DEPARTMENT OF COMMERCE } \\
\text { WASHINGTON, D.C. } 20234\end{array}$} & $\begin{array}{l}\text { 10. Project/Task/Work Unit No. } \\
2764144 / 2724448 \\
\text { 11. Contract/Grant No. } \\
\text { P.O. No. FY-567495 }\end{array}$ \\
\hline \multicolumn{3}{|c|}{$\begin{array}{l}\text { 12. Sponsoring Organization Name and Address } \\
\text { Jet Propulsion Laboratory } \\
\text { Pasadena, California, } 91103\end{array}$} & $\begin{array}{l}\text { 13. Type of Report \& Period } \\
\text { Covered } \\
\text { Final } \\
\text { 14. Sponsoring Agency Code }\end{array}$ \\
\hline
\end{tabular}

15. SUP PLEMENTARY NOTES

16. ABSTRACT (A 200-word or less factual summary of most significant information. If document includes a significant bibliography or literature survey, mention it here.)

A coaxial precision waveguide-below-cutoff attenuator is described which utilizes an absolute (unambiguous) electronic digital readout of displacement in inches in addition to the usual gear-driven mechanical counter/dial readout in decibels. The attenuator is rackmountable and has the input and output rf connectors in a fixed position. The attenuation rate for 55, 50, and $30 \mathrm{MHz}$ operation is given along with a discussion of sources of errors. In addition, information is included to aid the user in making adjustments on the attenuator should it be damaged or disassembled for any reason.

17. KEY WORDS (Alphabetical order, separated by semicolons)

Absolute (unambiguous) readout; piston; precision attenuator; sensor; waveguide-below-cutoff.

18. AVAILABILITY STATEMENT

UNL IMI T ED.

FOR OFFICIAL DISTRIBUTION. DO NOT RELEASE TO NTIS.
19. SECURITY CLASS (THIS REPORT)

UNCL ASSIFIED

20. SECURITY CLASS (THIS PAGE)

UNCL ASSIFIED
21. NO. OF PAGES

22. Price 